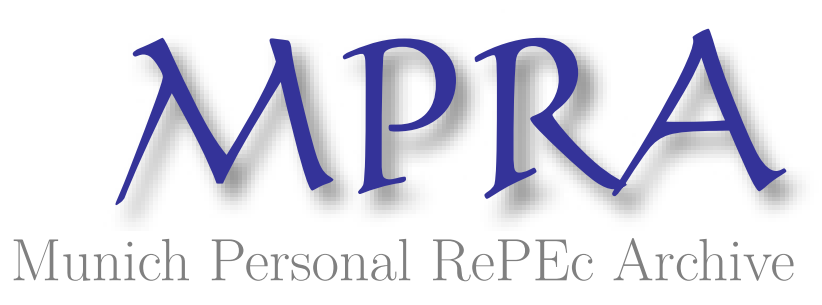

\title{
Governance and Group Conflict
}

Kölle, Felix

University of Cologne

January 2020

Online at https://mpra.ub.uni-muenchen.de/98859/

MPRA Paper No. 98859, posted 29 Feb 2020 15:51 UTC 


\title{
Governance and Group Conflict
}

\author{
Felix Kölle* \\ University of Cologne
}

This version: January 2020

\begin{abstract}
Many situations in the social and economic life are characterized by rivalry and conflict between two or more competing groups. Warfare, socio-political conflicts, political elections, lobbying, and R\&D competitions are all examples of inter-group conflicts in which groups spend scarce and costly resources to gain an advantage over other groups. Here, we report on an experiment that investigates the impact of political institutions within groups on the development of conflict between groups. We find that relative to the case in which group members can decide individually on their level of conflict engagement, conflict significantly intensifies when investments are determined democratically by voting or when a single group member (the dictator) can decide on behalf of the group. These results hold for both symmetric and asymmetric contests, as well as for situations in which institutions are adopted exogenously or endogenously. Our findings thus suggest that giving people the possibility to vote is not the main reason for why democracies seem to engage in less wars than autocracies. Nevertheless, when giving participants the possibility to choose which institution to adopt, we find that the voting institution is the by far most popular one as it combines the desirable features of autonomy and equality.
\end{abstract}

Keywords: Conflict, competition, institutions, democracy, groups, experiment

JEL Classification Numbers: D72; C72; C92.

*Felix Kölle, University of Cologne, Albertus Magnus Platz, 50923 Cologne, Germany, Phone: +49 (0)221 470 5489, E-mail: felix.koelle@uni-koeln.de. We thank Oliver Gürtler, Johannes Münster, Christoph Schottmüller, as well as various conference and seminar participants for helpful comments. Financial support from the Center for Social and Economic Behavior (C-SEB) at the University of Cologne and the UniCredit foundation is gratefully acknowledged. 


\section{Introduction}

Many situations in the social and economic life are characterized by rivalry and conflict between two or more competing groups. Warfare, socio-political conflicts, political elections, lobbying, rent-seeking, and R\&D competitions are all examples of inter-group conflicts in which groups spend scarce resources to compete with other groups. Conflicts of these types can be very costly for the involved parties, as well as the society as a whole, as they often entail activities that have no direct productive value. Understanding the causes and consequences of conflict, and developing solution mechanisms that mitigate conflict, is therefore of major importance. Conflict prevention has been recognized as one of the main societal chal-

lenges for Europe (Horizon 2020), and researchers from various disciplines have long been interested in the determinants of conflict, including economics (Garfinkel and Skaperdas, 2007), psychology (Sherif et al., 1961; Tajfel, 1982), and the political sciences (Ramsbotham et al., 2011).

In this paper, we investigate the role of different types of governance structures on the development of conflict. The motivation for this comes from the simple observation that groups are typically not created equal, but differ with regard to the way the are organized. For example, while some countries are governed by democracies, some others are ruled by autocratic regimes. Moreover, while some organizations are best characterized by flat hierarchies, others have adopted more hierarchical organizational structures. Similarly, while some team-leaders in companies exhibit more autocratic leadership styles, some others promote more independence and active engagement by its members. Previous research has documented the importance of leadership for a variety of outcomes including organizational performance, worker motivation, and job satisfaction (see e.g., Bass, 2009, for an overview). It has further been argued that governance structures also matter for the degree to which groups engage into conflict. In particular, in international relations, according to "democratic peace theory" (e.g., Russett, 1993), it is an empirical regularity that wars between two democratic countries occur less frequently than wars in which at least one of the two involved parties is a nondemocratic country. While different explanations have been put forward to explain this phenomenon (see e.g., Maoz and Russett, 1993; Owen, 1994; De Mesquita et al., 1999; Jackson and Morelli, 2007, for a review of some of these arguments), deriving clean causal evidence from these studies is difficult. The reason is that the empirical findings are almost exclusively based on historical data, which have the inherent problem that the political institutions that are studied are typically adopted endogenously, and the countries investigated typically differ along a variety of dimensions. 
Here, we pursue an alternative strategy, aimed at providing clean causal evidence on the effects of governance on conflict as well as its underlying mechanisms. For this purpose, we designed a controlled laboratory experiments, addressing the following three research questions. First, does exogenously manipulating the political institution within a group has a causal impact on its engagement into conflict? Second, which institutions emerge endogenously in these type of situations when individuals are given the possibility to vote for their preferred option? Third, does the governance structure has differential effects on conflict investments depending on whether it is assigned exogenously are adopted endogenously?

As a workhorse for studying group conflicts, we use a version of Tullock's lottery contest game (Tullock, 1967; 1980), in which two groups compete for a prize that is divided equally among all members of the winning group (Katz et al., 1990; Münster, 2009; Konrad, 2009). Within this simple setup, we analyze three different types of institutions, determining the way groups decide on their conflict investments. In the first institution, each group member can individually decide how much of his or her resources to invest into the conflict. We refer to this situation as Autonomy, as each group member has full sovereignty about the own degree of conflict engagement. In the second institution, which we call Democracy, an individual's conflict investment is determined by voting. In particular, each group member first votes on a collective investment level by making a proposal. Then, the median proposal within each group is implemented for all group members. Finally, in the third type of institution one randomly selected group member is given the sole decision power to determine the conflict investment of each group member. We differentiate between two different versions of this type of autocracy, varying whether the selected group member can fully discriminate between own and others' investments, or not. We refer to these two situations as Dictatorship and Restricted Dictatorship, respectively.

In the first part of the experiment, groups are randomly matched into pairs, and, within each pair, groups are randomly assigned one of the four institutions. The results from this first part reveal that the way groups are structured has a significant impact on the degree of conflict. In line with our theoretical predictions (see Section 3), we find that, relative to the Autonomy, conflict investments significantly increase in both the Democracy and the two types of dictatorship. Contrary to our expectations, however, we find no significant differences between the Democracy and the Dictatorship, indicating that giving people the possibility to vote per se has no direct causal effect on the intensity of group conflict. Individual-level analysis reveals that one reason for the absence of any pronounced differences between the Democracy and the two types of dictatorship is the fact that only a minority of participants in the role of the dictator use their decision power to fully discriminate between themselves and their group members. Yet, while these institutions are comparable in terms 
of average payoffs, they differ with regard to the level of inequality within groups.

At the beginning of the second part of the experiment, participants were introduced to all four institutions. Subsequently, they were given the opportunity to choose which institution to adopt using approval voting (Brams and Fishburn, 1978). After the voting procedure, groups were randomly formed and re-matched, and the institution with the largest number of votes was implemented. Hence, in contrast to the first part of the experiment, institutions are now chosen endogenously rather than assigned exogenously. Furthermore, since groups were randomly matched into pairs, both symmetric conflicts between two groups of the same institution, as well as asymmetric conflicts between two groups with different institutions could emerge.

Our voting results reveal that the Democracy is the by far most popular institution, followed by the Autonomy and the Restricted Dictatorship. Individual voting patterns suggest that many participants have a preference for autonomy, i.e., the ability to choose the own conflict engagement in a self-determined way, and fairness, i.e., the idea that each group member should contribute equally to the group's success. With regard to conflict engagement, we find that the institution of both the own group and the opponent's group matter for the intensity of the conflict. Specifically, we find that groups who adopt the Autonomy invest significantly less into conflict than any other group, and that holding constant the own group's institution, conflict investments are always lowest when the opponent group is governed by an Autonomy. No pronounced differences are observed between the other types of institutions. Finally, when comparing the results between the two parts of the experiment, we find little evidence for the hypothesis that the way an institution is adopted (endogenously or exogenously) matters for its effect on conflict.

Our paper provides some novel insights into the determinants of group conflict. In particular, it demonstrates the importance of political institutions for the development of conflict, and shows which governance structures are preferred by the participants of the conflict. With regard to the "democratic peace theory", our results suggest that the implementation of democratic structures per se (at least the way as operationalized here) may not be the main reason for why democracies seem to go to war less often than non-democratic countries (see Section 6 for a more detailed discussion). Nevertheless, if given the choice, individuals prefer the democracy as it guarantees them autonomy and protects them from exploitation by others.

More generally, our paper contributes to the economic literature on group contest, which has investigated various determinants of conflict, including group size, the sharing rule, the production function, and the contest success function, among others (see Konrad (2009) for 
an overview of the theoretical literature, and Sheremeta (2018) for an overview of the experimental literature). A few studies have investigated the role of other types of institutions on group conflict. For example, Abbink et al. (2010) show that allowing costly punishment within groups leads to an intensification of conflict and significant efficiency losses. Similar negative effects have been found when allowing communication within groups, while the opposite effect is observed when allowing for communication between the competing parties (Sutter and Strassmair, 2009; Cason et al., 2012; Leibbrandt and Sääksvuori, 2012; Cason et al., 2017). Heine and Riedl (2019) study the role of leadership on group contest. They find that leading-by-example increases conflict expenditures, unless communication between groups is possible. ${ }^{1}$ While these type of institutions are quite distinct from the ones considered here, the results from our and these previous studies are consistent in the sense that the same institutions that have been shown to have positive welfare effects in some situations such as social dilemma problems (e.g., Ostrom et al., 1992), might have opposite effects in other contexts such as the one considered here.

Our paper further contributes to the literature investigating the efficacy of institutions depending on whether they are imposed endogenously (through a democratic process) or exogenously. Previous literature has demonstrated that economic policies often have a greater impact when chosen by vote. Such "dividend of democracy" has been demonstrated across many different settings including rule violation (Bardhan, 2000), tax morale (Torgler, 2005), work performance (Mellizo et al., 2014), and labor supply (Sausgruber et al., 2019). Furthermore, in experimental settings several papers have shown that punishment institutions are more effective in promoting cooperation when adopted endogenously rather than exogenously (Tyran and Feld, 2006; Kosfeld et al., 2009; Dal Bó et al., 2010; Sutter et al., 2010; Markussen et al., 2013). Here, we compare endogeneous vs. exogenous institutions in the context of group conflict, an exercise which (to the best of our knowledge) has not yet been made. In contrast to the evidence from these previous studies, in our context we find little evidence for a "dividend of democracy".

The rest of the paper is organized as follows. In Section 2, we explain the general decision situation as well as the experimental design and procedures. Section 3 provides theoretical benchmark predictions for the expected level of conflict. In Section 4, we report our findings of how different types of institutions affect conflict. After that, in Section 5 we discuss which institutions are adopted endogenously when giving individuals the possibility to vote, and how these endogenously adopted institutions affect investments in both symmetric and asymmetric contests. Section 6 concludes.

\footnotetext{
${ }^{1}$ Relatedly, Eisenkopf (2014) studies the effects of advice giving by (impartial) managers on team competition.
} 


\section{The experiment}

We start by introducing the basic decision situation. We then describe the different governance structures. After that, we explain the exact experimental design and procedures.

The basic decision situation. The basic decision situation is an adaption of the classical Tullock contest model (Tullock, 1967), applied to a situation in which two groups $(j=$ $1,2)$ of $n=3$ players each compete for a prize that is shared equally among the members of the winning party (Katz et al., 1990). The prize thus constitutes a public good, with an individual valuation of $v$. Initially, each player is endowed with the same amount of resources, $\omega$. All players have to simultaneously and independently decide how much of their endowment they want to invest into the conflict. While spending effort is costly for the individual, it increases the chance of the own group winning the contest. The performance of the group thereby depends on the joint effort of all members, i.e., efforts are perfect substitutes. Formally, let $x_{i, j}$ denote the effort (resources) spend by player $i$ in group $j$. A group's performance is then determined by the sum of all efforts, $X_{j}=\sum_{i=1}^{n} x_{i, j}$. The

probability of winning the contest depends on the relative performance of both groups. Following Tullock (1980), we use the following contest success function:

$$
p_{j}\left(X_{1}, X_{2}\right)=\left\{\begin{array}{cl}
\frac{X_{j}}{X_{1}+X_{2}} & X_{1}+X_{2}>0 \\
\frac{1}{2} & \text { otherwise }
\end{array}\right.
$$

The expected payoff of player $i$ in group $j$ is thus given by

$$
\pi_{i, j}\left(x_{i, j}, X_{1}, X_{2}\right)=\omega-x_{i, j}+p_{j} \cdot v
$$

Institutions. Within this basic setup, we analyze four different institutions, determining the way groups decide on their conflict investment. In the first institution, the setup is exactly as described above: group members decide simultaneously and independently from each other how much of their resources (between 0 and $w$ units) to invest into the conflict. Each unit not invested into the conflict automatically remains on an individual's private account. We refer to this institution as Autonomy (AUT).

In the second institution, in contrast, an individual's investment decision is determined by voting. In particular, each group member can make a proposal by submitting a common investment level $\tilde{x}$. Subsequently, the median proposal within each group is implemented for 
each member. ${ }^{2}$ As a consequence, investment levels (and thus payoffs) are the same for all members within a group. In the following, we refer to this institution as Democracy (DEM).

In the third and fourth institution, the decision power over conflict investments lies in the hands of a single, randomly selected, group member, the dictator. ${ }^{3}$ In the first case, the dictator can implement any possible vector of investment levels, $\mathbf{x}=\left(x_{i}, x_{k}, x_{l}\right)$, where $x_{i}, x_{k}, x_{l} \in[0, \omega]$ are the investment levels of himself $(i)$, group member $k$, and group member $l$. In the second case, the dictator is forced to implement the same investment level for each group member, i.e., $x_{i}=x_{k}=x_{l}$. Hence, while in the first case the dictator can discriminate between himself and the other group members, in the latter this is no longer possible. We refer to these institutions as Dictatorship (DIC) and Restricted Dictatorship $(R D I C)$, respectively. In both cases, the other group members are passive players who have no task but to follow the dictator's decision.

Experimental design. Our experiment consists of two parts, Part 1 and Part 2. At the beginning of Part 1, groups of $n=3$ players were randomly formed. Two groups were then randomly matched to compete in a conflict for 20 identical periods using a partner matching protocol, capturing the dynamic pattern of group conflicts inherent in many real-world situations. Importantly, subjects were only exposed to one of the four possible institutions (between-subjects design). That is, the institution within a group remained constant throughout the twenty periods, and the institution in the two competing groups was always the same (symmetric contests). In the dictator treatments, at the beginning of the experiment one subject in each group was randomly assigned the role of the dictator, and this subject remained in this role for all twenty periods. In each period, subjects received an endowment of $\omega=100$ tokens, and the group could win a prize of $n v=300$. In case of success, each subject of the winning group received an equal share of $v=100$, irrespective of their own investment. At the end of each round, subjects received detailed feedback about the individual decisions in their own group, as well as aggregate information about the decisions in the opponent group. After that, a new round started.

At the beginning of Part 2, groups were dissolved and subjects were randomly re-matched

\footnotetext{
${ }^{2}$ See, e.g., Bernard et al. (2013) for a similar procedure in a different context. As in their case, we chose this aggregation rule for two reasons. First, given that in our experiment there were 101 different possible investment levels (see below), majority rule oftentimes might have failed to pick a winner. In this case, one either would need to decide on a rule for tie resolution, or allow for multiple rounds of voting, which is very time-consuming. Second, under the assumption of single-peaked preferences among voters, theory predicts that the median voter's choice would ultimately be implemented. Therefore, we decided to implement the median vote straight away as a reasonable shortcut.

${ }^{3}$ In the experimental instruction (see Appendix C), neutral language was used to describe institutions and player roles.
} 
into new groups. They then received a detailed description about each of the four institutions. After that, subjects had to decide which institution to adopt for their own group in Part 2. To determine a group's institution we used the approval voting mechanism in which voters can vote for ("approve of") as many options as they want (Brams and Fishburn, 1978). ${ }^{4}$ In our case, subjects had to state for each institution whether they want to support this institution or not. Before the start of the voting procedure, it was explained to subjects that the institution with the highest number of approvals within their group would be implemented (ties were broken at random), and that their group had to compete under this institution against another randomly selected group for twenty periods. Given that the voting procedure only decided on the institution within the own group, it was also made clear to subjects that the institution of the own and the opponent's group could differ. Thus, in contrast to Part 1 where only symmetric contests between two identical groups were possible, in Part 2 asymmetric contests between groups with different institutions could emerge. After the voting procedure, subjects were informed about which institution their own and the opponent's group adopted. In case one of the dictator treatments was chosen, groups were also informed about which subject was randomly assigned the role of the dictator. Groups then played the inter-group contest game for 20 consecutive periods as described above.

Procedures. At the beginning of the experiment, subjects were informed about the twopart nature of the experiment. Subjects were then introduced to the basic decision situation and the details of Part 1. After that, subjects had to successfully complete a comprehension test consisting of several questions about the rules and the comparative statics of the game (see Appendix $\mathrm{C}$ for an English version of the instructions as well as a a copy of the control questions). Only after all subjects answered all control questions correctly, Part 1 began. After the end of Part 1, subjects received instructions about the details of Part 2. At the end of the experiment, subjects received an overview of their earnings, which were determined by the sum of their payoffs from Part 1 and Part 2. In addition, each subject received a show-up fee of $€ 4$. On average, subjects earned around $€ 13$, and sessions lasted about 90 minutes. We ran twelve sessions with a total of $n=354$ students ( $A U T: n=84, D E M$ : $n=90, D I C: n=90, R D I C: n=90)$, recruited from various disciplines using the online recruiting software ORSEE (Greiner, 2015). ${ }^{5}$ The experiment was computerized using z-Tree (Fischbacher, 2007).

\footnotetext{
${ }^{4}$ Approval voting has been previously used both in the lab (e.g., Sutter et al., 2010) and the field (e.g., Laslier and Van der Straeten, 2008). According to Laslier and Van der Straeten (2008), it is easily understood and well accepted by voters. See Weber (1995) for a theoretical analysis and Brams and Fishburn (2007) and Laslier and Sanver (2010) for an overview of the literature.

${ }^{5}$ The slightly lower number of observations in the Autonomy treatment was due to a low show-up rate in one of the sessions.
} 


\section{Benchmark predictions}

Under the assumption that players are risk-neutral and only motivated by their own monetary payoffs, the unique symmetric Nash equilibrium prediction in the stage game of the Autonomy treatment stipulates that total group investments are equal to $X_{1}=X_{2}=\frac{v}{4}=25$ (see Appendix B for details). Note that while this prediction is unique with regard to the overall investments within a group, it remains silent about how group members share the burden of contributing to the group's success; any combination of investments by the three group members that add up to 25 constitutes an equilibrium (compare Katz et al., 1990; Baik, 1993; Konrad, 2009; Münster, 2009). This is due to the fact that group members have identical prize valuations and that marginal costs of investments are constant. As a result, given the equal-sharing rule within groups, the prize constitutes a local public good and, thus, group members face the typical free-rider problem inherent in many social dilemma problems (Hardin, 1968; Olson, 1965; Ostrom et al., 1994).

The predictions are less clear in the Democracy treatment, as any profile in which all players in a group make the same proposal is a Nash equilibrium, because the median vote will not change if any single player changes her vote. As a result, there is a vast range of symmetric Nash equilibria, including one in which all players propose zero investments as well as one in which all members propose maximum investments. In addition, there are also multiple asymmetric equilibria in which proposals are the same within but not between groups. Given this multiplicity of equilibria, predictions are not straightforward as players face a non-trivial coordination problem.

This changes, however, if, as a refinement criterion, we assume that within a group, individuals coordinate on an investment level that is Pareto efficient from a group's point of view, that is, if we only focus on those equilibria which are robust against joint deviations from a coalition of players within the same group. This refinement criterion is related to the concepts of strong Nash equilibrium (Aumann, 1959) or coalition-proof Nash equilibrium (Bernheim et al., 1987), and has been applied to similar contexts before (see e.g., Gürtler, 2008). To illustrate the intuition behind this refinement, imagine the situation in which all players in both groups propose an investment level of zero. This situation constitutes a Nash equilibrium as no player has an incentive to deviate unilaterally. Yet, all group members would prefer to jointly deviate to a different strategy profile, where, again, no player has an incentive to unilaterally deviate. For instance, if the rivaling group invests nothing into the

conflict, all individuals in the other team would be strictly better off when jointly deviating from a strategy profile of zero (in which case they would win the contest with probability 
0.5) to, e.g., a strategy profile of one, in which case the group would win the conflict with certainty.

Applying this logic to both groups, it follows that the only remaining Nash equilibria are the ones in which total investments in both groups are equal to $X_{1}=X_{2}=\frac{n v}{4}=75$. The intuition for this result is straightforward. When deviating jointly and increasing the proposed investment level by one unit, a group's total investment level increases by $n$ units (each of the $n$ group members has to follow the binding vote and increase their investment by one unit). Yet, each individual only bears a share of $\frac{1}{n}$ of the total investment costs. As a result, given our group size of $n=3$, the prediction for the total group investments is three times higher than in the situation in which each individual decides autonomously. Note, however, that while this prediction is unique with regard to a group's total investment, similar to the case of the autonomy, there are multiple equilibria with regard to the individual proposals. Specifically, any combination of proposals where the median proposal is equal to 25 constitutes an equilibrium. Furthermore, given the vast range of possible equilibria, a priori it is not clear whether individuals manage to coordinate on this or a different equilibrium. The answer to this question is an ultimately empirical one we can test with our data.

In the Dictatorship treatment, it is obvious that if dictators are purely self-interested they should always invest the whole endowment of the two group members as any unit invested into the conflict by others increases the group's chance of winning (and hence the dictator's expected benefit) without involving any material costs to the dictator. As a result, given our endowment level of $\omega=100$, total group investments should be equal to $(n-1) \cdot \omega=200$, at a minimum. Of course, dictators are free to even further increase these investments by using their own endowment. Given the non-linearity of the contest success function (see equation (1)), however, it turns out that this is not optimal. That is, at the point where both groups invest 200 units each, the marginal costs of increasing the group investment even further outweigh the marginal benefits. Formally, the dictator would only be willing to invest himself if the total investments by the other group members are sufficiently small, i.e., in case if $\omega<\tilde{\omega}=\frac{v}{4(n-1)}$. In our setup, this threshold is equal to 12.5 as in this case, the joint investments of both other group members would be lower than 25 , the optimal level in case all group members can decide individually (see above). Hence, given our parameters, $X_{1}=X_{2}=200$ with $X_{j}\left(x_{i}, x_{k}, x_{l}\right)=(0,100,100)$ is the only Nash equilibrium in the Dictator treatment.

This prediction changes, when, as in our Restricted Dictatorship treatment, dictators can no longer discriminate between themselves and their group members. In this case, the incentives are similar to a coalition of players in the Democracy treatment, or a single 
player who knows or believes with certainty that he or she is pivotal; in both cases the coalition/individual can enforce an one-unit increase of investments by all group members while only having to pay a fraction of $\frac{1}{n}$ of the total investment costs. Hence, similar to the logic of the refinement criterion of group Pareto efficiency as applied above, it thus follows that in equilibrium total investment levels in the Restricted Dictatorship treatment are equal to $X_{1}=X_{2}=\frac{n v}{4}=75$. Note, however, that in contrast to the Democracy treatment, here this Nash equilibrium is unique. Furthermore, while dictators in the Restricted Dictatorship treatment know for sure that they are pivotal (they are the only group members with decision power), individuals in the Democracy treatment face strategic uncertainty with regard to their group members' voting behavior. As a consequence, subjects in the latter do not know whether they will be pivotal or not, and there were no straightforward tools such as communication to form coalitions. As a result, while at the group level we might expect similar levels of investments across the two treatments, individual investment patterns might differ between the two treatments. We will come back to this issue in the results section, when investigating whether this strategic uncertainty matters for individuals' voting behavior.

Table 1 provides a summary of our experimental treatments including the number of observations in each treatment as well as the theoretical predictions derived above. Table 1 further highlights two important dimensions that characterize our four different institutions. The first dimension concerns subjects' autonomy. Autonomy (or self-governance) can be described as an individual's capacity to act according to their own values and convictions, and to make informed and uncoerced decisions in the absence of any manipulative or distorting external forces (Christman, 2008). Autonomy plays a central role in theories of moral and political philosophy, and is seen as a non-instrumental value that should be respected (Rawls, 1971; Feinberg, 1978; Young, 1982). In social psychology, autonomy is a key component in self-determination theory, and is thought to be essential for people's motivation, social development, and personal well-being (Ryan and Deci, 2000). More recently, economic studies have demonstrated that individuals value decision rights intrinsically, beyond their mere instrumental benefit (Bartling et al., 2014). Applying the concept of autonomy to our setting, it is clear that autonomy is high under the Autonomy and Democracy institution as individuals can freely decide on their (proposed) conflict investment. In the two Dictatorship treatments, in contrast, autonomy is low as no one except the dictator can make self-determined decisions.

The second dimension that distinguishes our different institutions is whether inequality in payoffs within groups is possible or not. Previous studies have demonstrated that many people are not only motivated by their own material payoffs, but also by the well-being of others. While such other-regarding concerns come in various forms and shapes (see e.g., 
Table 1: Experimental treatments

\begin{tabular}{lcccc}
\hline Treatments & $\begin{array}{c}\text { \# Subjects } \\
\text { (conflicts) }\end{array}$ & $\begin{array}{c}\text { All group } \\
\text { members have } \\
\text { a say }\end{array}$ & $\begin{array}{c}\text { Inequality } \\
\text { within groups } \\
\text { possible }\end{array}$ & $\begin{array}{c}\text { Benchmark } \\
\text { prediction }\end{array}$ \\
\hline Autonomy (AUT) & $84(14)$ & $\checkmark$ & $\checkmark$ & 25 \\
Democracy (DEM) & $90(15)$ & $\checkmark$ & $\mathrm{x}$ & $75^{*}$ \\
Dictatorship (DIC) & $90(15)$ & $\mathrm{x}$ & $\checkmark$ & 200 \\
Restricted Dictatorship (RDIC) & $90(15)$ & $\mathrm{x}$ & $\mathrm{x}$ & 75 \\
\hline
\end{tabular}

Notes: Benchmark predictions show the predicted level of total group investments in the stage game. Given that the number of periods was common knowledge, the prediction of the stage game coincides with the subgame-perfect Nash equilibrium of the finitely repeated game.* For the Democracy treatment, the prediction is derived using the additional assumption that group members coordinate on the equilibrium in which no coalition within a group has an incentive to jointly deviate.

Sobel, 2005; Fehr and Schmidt, 2006; Cooper and Kagel, 2016, for overviews of the literature), one fundamental psychological element underlying many of these theories are social comparisons (Festinger, 1954; Adams, 1963). In particular, there are many people who dislike inequality, i.e., situations in which their own payoff exceeds or falls short the payoffs of others (e.g., Loewenstein et al., 1989; Fehr and Schmidt, 1999; Bolton and Ockenfels, 2000). Such inequality concerns should not affect behavior in our Democracy and Restricted Dictatorship treatment, as in these contexts inequality within groups is ruled out by design. In the Autonomy and Dictator treatment, in contrast, inequality is possible and hence might shape behavior. While in the latter the degree of inequality lies entirely in the power of the dictator, in the former group members can avoid inequality by coordinating their investment decisions.

Based on these considerations alone, the Democracy appears to be the most attractive institution, as it combines the two desirable features of self-determination and equality. The Autonomy also ensures self-determination, but might lead to inequality in case group members fail to coordinate on a common investment level. The Restricted Dictatorship, in contrast, ensures equality within groups but lacks autonomy as only one out of the three group members has decision power. Finally, the Dictatorship seems to be the least attractive as it both lacks autonomy and potentially creates inequality. In fact, inequality is predicted in equilibrium if dictators are purely selfish. Understanding how individuals value and rank these and other (e.g., strategic) dimensions of the different institutions in a context like ours is an interesting question, one we will investigate when analyzing the second part of our experiment in which subjects were given the opportunity to vote on each of the four possible institutions. 


\section{The role of institutions on group conflict}

We structure our analysis as follows. We start by describing the effects of the different institutions in Part 1 of the experiment on the intensity of conflict at the aggregate level. We then zoom into the individual-level, and describe the underlying behavior and mechanisms. In Section 5, we then describe the voting and conflict behavior in Part 2 of our experiment, where institutions could be adopted endogenously.

\subsection{Aggregate results}

Our main result is summarized in Figure 1. The left panel shows, for each treatment, the mean group investment into conflict, averaged over all twenty periods in Part 1 (see Figure A1 in Appendix A for the full distribution of investment decisions). The results demonstrate that the intensity of conflict significantly differs across treatments (KruskalWallis test, $p=0.001){ }^{6}$ A closer look reveals that this result is mainly driven by the Autonomy treatment, in which we observe the lowest conflict expenditures. Groups in this treatment invest on average 94.4 tokens into the conflict, which is significantly less than in any of the other three treatments (pairwise Mann-Whitney $\mathrm{U}$ tests, all $p<0.008$ ). In the remaining three treatments, in contrast, conflict investments are remarkably similar. While in the Dictator treatment investment levels are highest reaching an average of 154.9, the differences compared to the Democracy (146.7) and the Restricted Dictatorship treatment (138.9) are rather small and statistically insignificant (pairwise Mann-Whitney U tests, all $p>0.271)$.

To put these investment levels into perspective, we can compare them to the benchmark predictions derived in Section 3 (see Table 1). In the Autonomy, the Democracy, and the Restricted Dictatorship treatment we observe investments levels that are significantly higher than what is predicted, a pattern that is commonly observed in these type of experiments (see Sheremeta (2018) for an overview and a discussion of potential explanations). In particular, investments exceed the theoretical predictions by $278 \%$ (Autonomy), 85\% (Democracy), and $77 \%$ (Restricted Dictatorship (Signrank tests, all $p<0.002$ ) ${ }^{7}$ In the Dictator treatment, in

\footnotetext{
${ }^{6}$ When using non-parametric tests, we collapse our data such that there is one observation per conflict pair, as observations within a conflict of two competing groups are not independent. All results are robust to using multilevel linear mixed-effects regressions, which take into account the hierarchical structure of our data (repeated observations of individuals that are nested within a contest of two competing groups).

${ }^{7}$ Keep in mind that the predictions for the Democracy treatment are derived using the additional assumption that players coordinate on the equilibrium that is Pareto efficient from a group's point of view. Without that assumption, any possible investment level constitutes an equilibrium. In this case, comparisons between predictions and actual behavior is not very meaningful.
} 

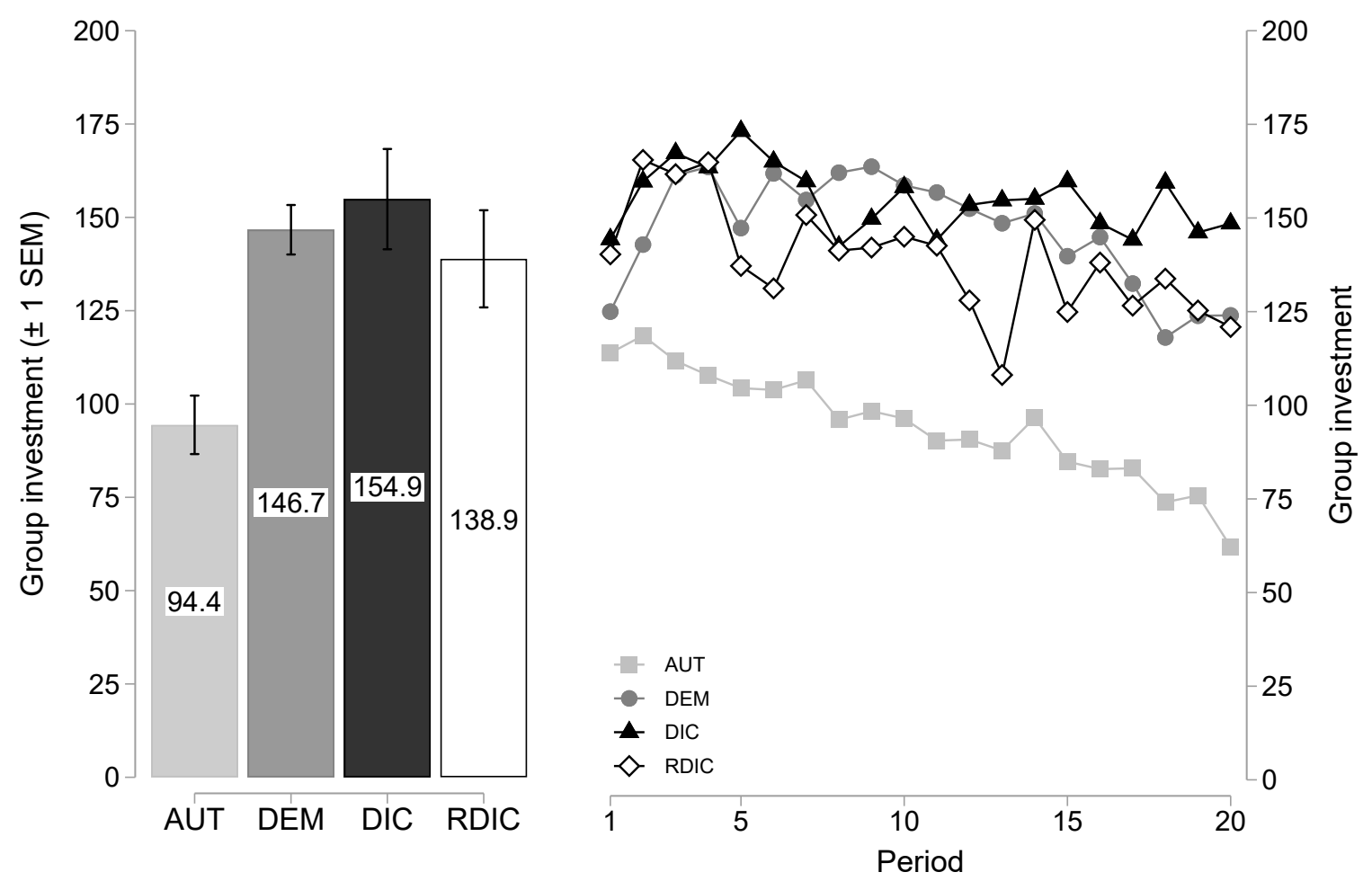

Figure 1: Left panel: Group conflict expenditures by treatment, averaged over all periods ( \pm 1 SEM). Right panel: Development of conflict expenditures over time.

contrast, we find investment levels to be significantly lower than what is predicted by theory $(-25 \%$, Signrank test, $p=0.013)$, an observation we will come back to in the next section.

The right panel of Figure 1 depicts the conflict dynamics over time. As can be seen, conflict investments in all treatments start off at rather similar levels, although the ordering of the treatments as described above is already present in the first round. Furthermore, in line with previous results (e.g., Abbink et al., 2010; Fallucchi et al., 2013), in the Autonomy treatment we observe a significant downward trend of investments over time. No such trend is observed in the remaining institutions, where investment levels are rather constant over time. As a consequence, the differences between the autonomy and the other institutions become particularly pronounced towards the end of the game, after subjects had gained some experience and after they had the opportunity to learn. The results further reveal that the non-existence of pronounced differences between the Democracy, the Dictatorship and the Restricted Dictatorship treatment is not an artifact of aggregating the data across rounds, but that these institutions cause a similar degree of conflict across all periods. ${ }^{8}$

\footnotetext{
${ }^{8}$ For example, when comparing conflict expenditures in the initial phase of the game (first 5 periods),
} 
These results are confirmed by multilevel linear mixed-effects regressions that take into account the inter-dependency of observations (repeated observations of individuals that are nested within a contest of two competing groups). The results are shown in Table A1 in the appendix. They reveal that $(i)$ conflict expenditures are significantly lower in the Autonomy relative to all other treatments, $(i i)$ that in the former there is a significantly steeper downward trend in investments, and (iii) that the differences across treatments are already significant in the very first period. We summarize these findings in our first result.

Result 1: Compared to the case in which members of a group can decide autonomously on their conflict expenditures, group conflict significantly intensifies when investments are determined by voting or by a single group member, with no pronounced differences among the latter.

To shed some light on the mechanisms that underlie the aggregate results described above, in the following two sections, we take a closer look at the individual-level behavior.

\subsection{Why does dictatorship not escalate conflict?}

The probably most surprising finding from above is that contrary to the theoretical predictions, group conflict does not escalate under the discriminatory dictatorship. To understand this result, in the following we have a closer look at the behavior of the dictators. Recall that dictators in the discriminatory dictatorship could implement any vector $\mathbf{x}=\left(x_{i}, x_{k}, x_{l}\right)$, where $x_{i}, x_{k}, x_{l} \in[0,100]$ are the investment levels of the dictator himself $(i)$, group member $k$, and group member $l$. Further recall that if dictators are purely self-interested, there is a unique equilibrium in which $x_{i}=0$ and $x_{j}=x_{k}=100$ (compare Section 3).

Figure 2 provides a summary of the dictators' behavior. It shows, for each period, the proportion of cases in which dictators decided that the other two group members had to invest (on average) more (top, lightgray-shaded, area), the same (middle, white-shaded, area), or less (bottom, darkgrey-shaded, area) to the group conflict than themselves. ${ }^{9}$ The results reveal that dictators use their power to exploit the other group members in only slightly more than half of the cases. Instead, in about $40 \%$ of the cases they implement

we find that investment levels in the Autonomy treatment are already significantly lower than in all other treatments (Mann-Whitney U tests, all $p<0.019$ ), while there are no differences among the latter (MannWhitney U tests, all $p>0.395$ ). When only considering data from the last five periods, a similar pattern is observed. While all comparisons with regard to the Autonomy treatment are significant (Mann-Whitney U tests, all $p<0.008$ ), none of the other comparisons is (Mann-Whitney $\mathrm{U}$ tests, all $p>0.221$ ).

${ }^{9}$ We use the average of the other two group members as in $94 \%$ of the cases, the dictator did not discriminate between the two. 


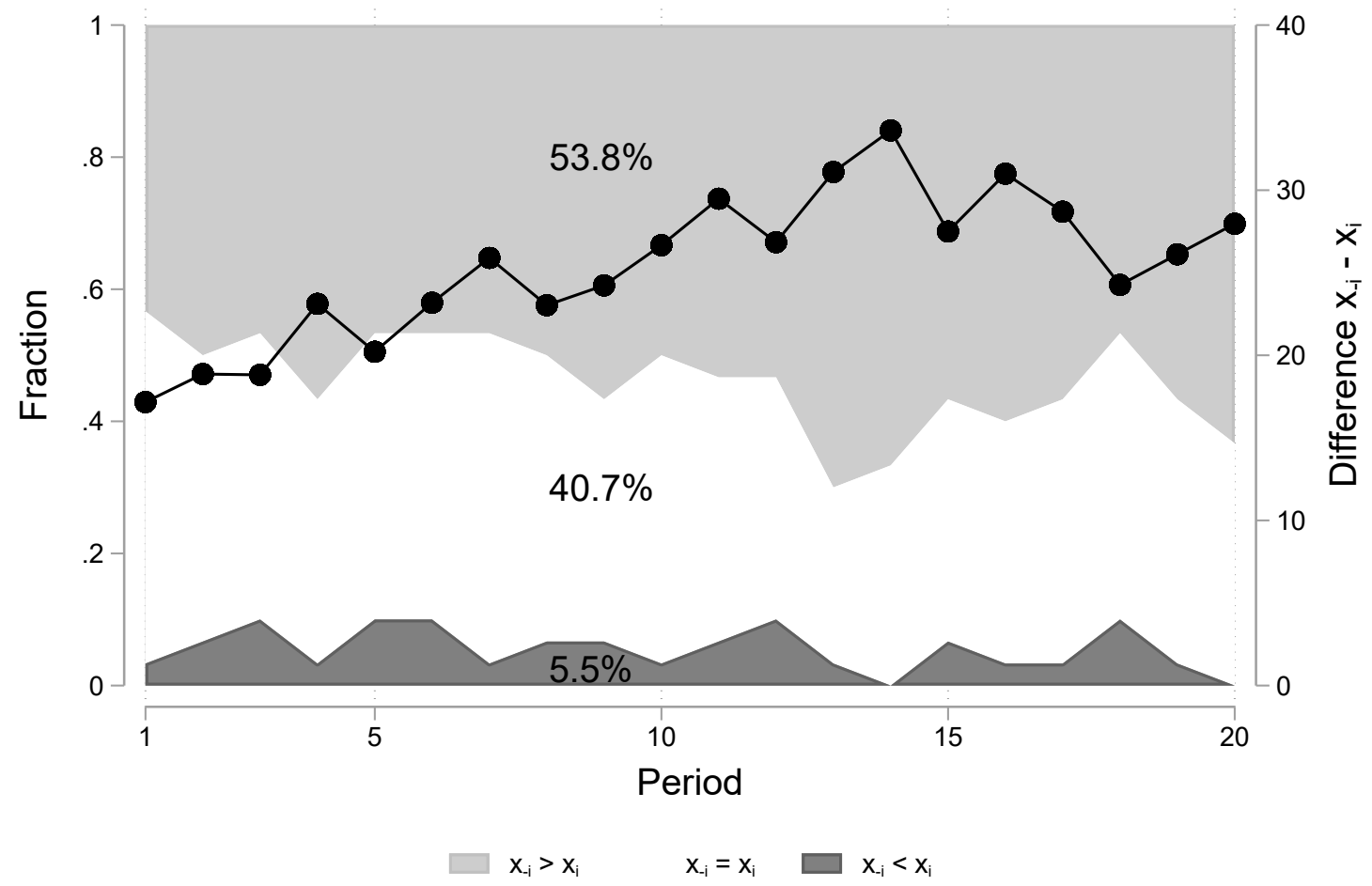

Figure 2: Fraction of decisions in which dictators decide to contribute less, the same, or more than their group members (left y-axis). Mean level of discrimination (right y-axis).

the same level of investment for all group members (including themselves), and in about $5 \%$ of the cases, dictators even chose an own investment level that exceeded the one they implemented for their group members.

Figure 2 further depicts the average degree of discrimination as measured by the difference between the other two group members' mean investment and the investment of the dictator. It reveals that the difference between the dictators' and their group members' investments significantly increases over time — from 17.2 in the first period to 28.0 in the last period (Signrank test, $p=0.034$ ) — indicating that dictators make more and more use of their discriminatory power the longer the game lasts. Yet, averaged over all periods, the implemented difference amounts to only 25.4 tokens, a quarter from what is expected if all dictators were fully rational and purely self-interested. The difference with regard to the theoretical benchmark of 100 is highly significant (Signrank test, $p<0.001$ ).

Taken together, Figure 2 reveals that dictators do not fully follow the prediction of full discrimination, at least not at the aggregate level. This, in turn, can explain why overall investment levels are significantly lower than what is predicted under the assumption of complete selfishness (see above), and this might further be the reason for why investment 


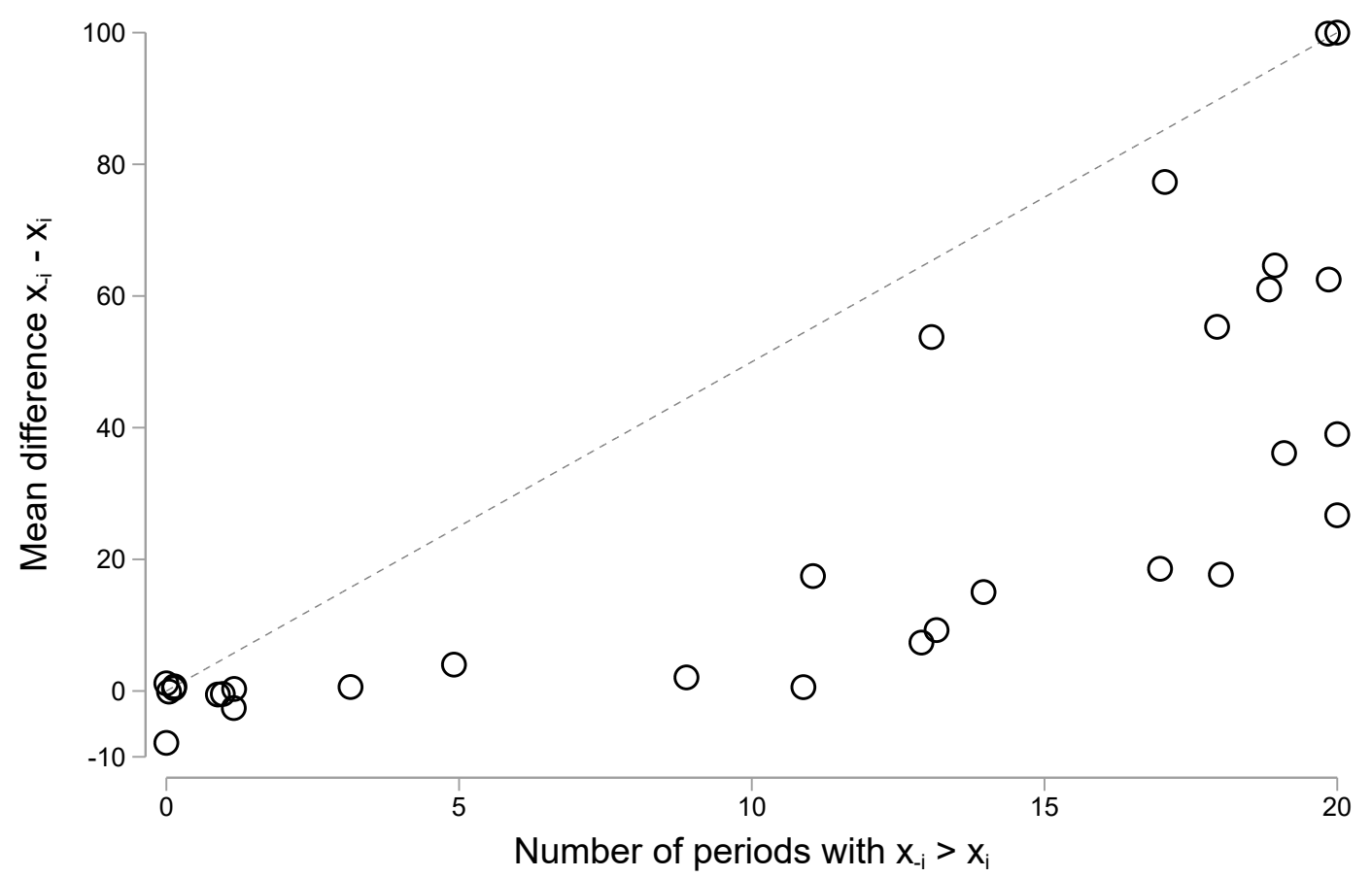

Figure 3: Heterogeneity of dictator behavior $(n=30)$

levels do not differ between the Democracy, the Dictatorship and the Restricted Dictatorship.

Yet, these results may mask important differences at the individual level, especially because previous literature has shown that there is pronounced heterogeneity with regard to people's other-regarding preferences (see e.g., Sobel, 2005; Fehr and Schmidt, 2006; Cooper and Kagel, 2016, for overviews of the literature). To uncover this heterogeneity, Figure 3 displays the dictators' behavior at the individual level, where each dot corresponds to one dictator. The $x$-axis depicts in how many out of the twenty periods a dictator chose to implement a vector of conflict investments in which they invested less than their group members. The $y$-axis shows the mean difference between the own and others' investments, averaged over all rounds (note that by construction only points below the dashed line are feasible).

The data reveals quite some pronounced heterogeneity between dictators, both with regard to the frequency as well as the intensity of discrimination. Broadly speaking, there are three different types of dictators. The first type is represented by the data points in the bottom left of Figure 3. These are dictators who never or only very rarely implement conflict investments in which they favor themselves by investing less than their group members. The second type of dictator, represented by the dots in the bottom right of the diagram, use the option to discriminate between themselves and their group members relative frequently, but 


\begin{tabular}{|c|c|c|c|c|c|c|c|}
\hline \multirow{2}{*}{ Type } & \multirow{2}{*}{ Frequency } & \multicolumn{3}{|c|}{ Investment level } & \multirow{2}{*}{$\%$ win } & \multirow{2}{*}{ Payoff } & \multirow{2}{*}{ Inequality } \\
\hline & & Own & Others & Total & & & \\
\hline Benevolent & $12(40 \%)$ & 51.39 & 51.28 & 153.94 & 0.50 & 98.61 & 1.54 \\
\hline Moderate & $10(33 \%)$ & 28.31 & 47.33 & 122.96 & 0.51 & 122.19 & 11.66 \\
\hline Selfish & $8(27 \%)$ & 17.66 & 89.26 & 196.19 & 0.49 & 131.71 & 41.40 \\
\hline
\end{tabular}

Notes: Inequality is calculated as the standard deviation of payoffs within a group. If dictators were completely self-interested, they should set $x_{i}=0$ and $x_{j}=x_{k}=100$, leading to the maximum possible level of inequality, which is equal to 57.735 .

Table 2: Dictator types and their performance.

the degree of their discrimination is, at least on average, rather moderate. Finally, the third type of dictator is represented by the dots in the upper right corner of the diagram. These are dictators who discriminate not only very frequently, but also quite intensively. Still, for only two dictators we observed the maximum possible degree of discrimination in all twenty periods. When looking at the relative frequency of these types, we find that roughly $40 \%$ fall under the first category, $33 \%$ fall under the second, and $27 \%$ fall under the third. In the following, we refer to these types as Benevolent, Moderate, and Selfish, respectively. ${ }^{10}$

Table 2 provides a summary of the outcomes for groups which are led by the different dictator types. Columns 3-5 show the mean investment levels dictators implement for themselves, their two group members, and the group as a whole. For all three measure, we find significant differences across types (Kruskal Wallis tests, all $p<0.007$ ). In particular, the results reveal that Benevolent and Moderate dictators differ with regard to their own investment (Mann-Whitney U test, $p=0.001$ ), but not with regard to others' investments (Mann-Whitney U test, $p=0.742$ ). The difference between Moderate and Selfish dictators, in contrast, mainly emerge from differences in investments implemented for others (MannWhitney $\mathrm{U}$ test, $p=0.001$ ), rather than themselves (Mann-Whitney $\mathrm{U}$ test, $p=0.328$ ). As a consequence, investment levels at the group level are u-shaped, amounting to 154, 123, and 196 tokens for Benevolent, Moderate, and Selfish dictators, respectively. ${ }^{11}$

Interestingly, while these different investment patterns do not translate into different likelihoods of winning the conflict (the average winning probabilities differ between $49 \%$ and 51\%; Kruskal-Wallis test, $p=0.983$ ), they matter for the dictators' payoff and the

\footnotetext{
${ }^{10}$ To classify types, we use the midpoint of each scale as cutoff values (10 for the $x$-axis and 50 for the $y$-axis). That is, we divide the diagram into four quadrants, and simply count how many observations are in each quadrant. While these cutoffs are somewhat arbitrary, they just serve the purpose of providing a rough classification. Qualitatively similar results are obtained when using alternative ways of classifying types.

${ }^{11}$ The p-values of the pairwise comparisons using a Mann-Whitney $\mathrm{U}$ test are: $p=0.065$ for Benevolent vs. Moderate, $p=0.045$ for Benevolent vs. Selfish, and $p=0.005$ for Moderate vs. Selfish.
} 
distribution of earnings within the group. ${ }^{12}$ In particular, discriminating between own and others' investment levels pays off for dictators in material terms, as column 7 reveals. The average payoff significantly differs across dictator types (Kruskal Wallis test, $p=0.013$ ) with Selfish dictators receiving the highest payoff, exceeding the ones of Moderate and Benevolent dictators by $34 \%$ (Mann-Whitney $\mathrm{U}$ test, $p=0.006$ ) and $8 \%$ (Mann-Whitney $\mathrm{U}$ test, $p=$ 0.248), respectively. This, however, comes at the cost of increased inequality as shown by the last column, displaying the mean standard deviation of payoffs within a group as a simple measure for inequality. Unsurprisingly, the data reveals that inequality significantly differs across types (Kruskal-Wallis test, $p<0.001$ ), with Selfish dictator groups implementing the highest and Benevolent dictator groups exhibiting the lowest degree of inequality. Yet, even for the selfish dictator types we find inequality to be lower than what is predicted by standard theory (Signrank test, $p<0.016$ ). We summarize these findings in our second result.

Result 2: Dictators only partly use their power to discriminate between their own and their group members' conflict investments. While the degree of discrimination increases over time, on average it amounts to only one quarter of what is predicted by pure self-interest, which explains why dictatorship does not escalate conflict. At the individual-level, we find pronounced heterogeneity across dictators. The largest group of dictators can be classified as benevolent, who in most of the periods implement the same level of investment for themselves and others.

\subsection{Voting behavior \& restricted dictatorship}

In this section, we take a closer look at the individual-level behavior in the Democracy and the Restricted Dictatorship treatment. Recall that both treatments share the feature that, by design, no inequality within groups is possible. They are further comparable with regard to the incentives of the decisive group member, i.e., the dictator or the median voter (see Section 3). Yet, while dictators in the Restricted Dictatorship treatment know with certainty that their decision will be implemented, participants in the Democracy treatment face strategic uncertainty with regard to their group members' proposals, and hence whether

\footnotetext{
${ }^{12}$ Note that we find some evidence for dependency of dictator types within a conflict pair. That is, in seven out of the fifteen independent conflicts $(46.7 \%)$, we find the dictators of both groups being the same type ( $n=2$ Benevolent, $n=2$ Moderate, and $n=3$ Selfish), which is somewhat higher than what would be expected if dictator types between groups were completely independent (given the underlying distribution of types, the expected frequency of same-type conflicts is equal to $34.2 \%$ ). In the remaining eight conflicts, the type of the dictator differs across the two groups, with $n=6$ being Benevolent-Moderate pairs and $n=2$ being Benevolent-Selfish.
} 

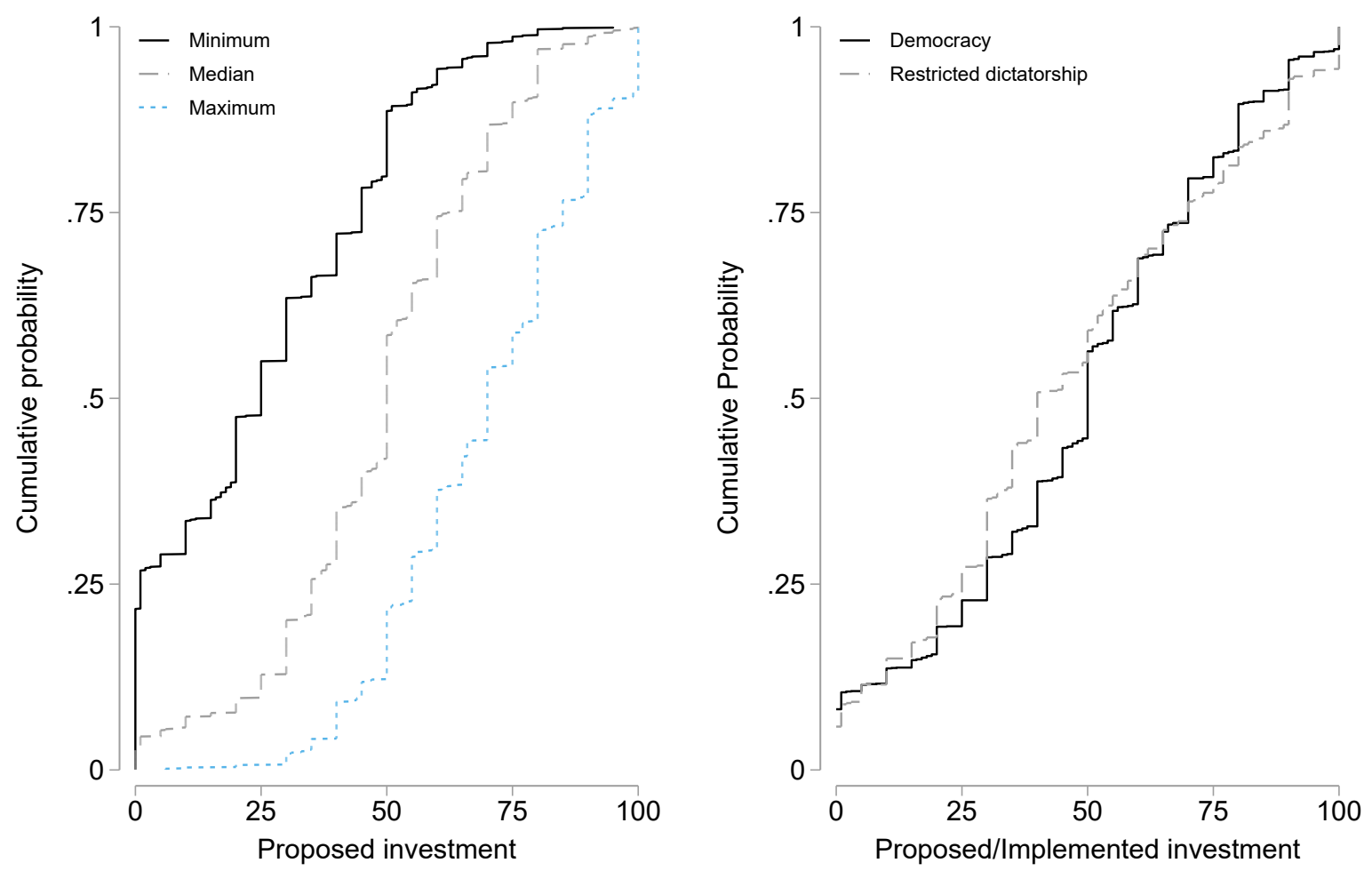

Figure 4: Left panel: Distribution of the minimum, median, and maximum vote in the Democracy treatment. Right panel: Distribution of proposed and implemented investment levels in the Democracy and Restricted Dictatorship treatment, respectively.

their own proposal will affect the group investment or not. By comparing the (proposed) investment levels between these two treatments, we can test how this uncertainty affects behavior, if at all.

We start by describing the voting behavior in the Democracy treatment. The left panel of Figure 4 plots the cumulative distribution of the minimum, median, and maximum proposed investment level. The distributions are quite different, with the average (median) vote amounting to 26.1 (25), 48.9 (59), and 69.7 (70), respectively. Furthermore, the average (median) range of proposals within a group (i.e., the difference between the minimum and the maximum proposal) amounts to 43.6 (40), indicating a fair amount of disagreement about what is best for the group. In $79 \%$ of the cases, these voting patterns led to a unique proposal that was implemented. In a further $20 \%$ of the cases there were two identical proposals, and in only $1 \%$ of the cases the proposals of all three group members coincided.

Figure A2 in Appendix A shows that these patterns are relatively stable over time, although we observe a slight increase in dispersion of proposals within groups. Specifically, 
when comparing the average range of proposals within groups between the first five and the last five periods, we find a significant increase in dispersion from 39.0 to 48.6 (Signrank test, $p=0.017) .^{13}$

When considering the dynamics of voting within groups, we observe that group members strategically adjust their proposals to those of their peers. That is, when only considering those $79 \%$ of cases in which all three proposed investment levels within a group and a given period were unique (i.e., when excluding those situations in which there were ties), we find that subjects who proposed the lowest investment level, in the next period adjust their proposal upwards (by +7.4 units, on average; t-test, $p<0.001$ ). ${ }^{14}$ Subjects who previously proposed the highest investment level, in contrast, adjust their proposal downwards $(-10.0$ units, on average; t-test, $p<0.001)$, while those whose proposal was pivotal, hold their proposal constant (on average), with a slight, but insignificant, upward adjustment of 0.6 units (t-test, $p=0.222$ ). Despite these adjustments, we observe quite some inertia with regard to the median voter. In $63 \%$ of the cases we find the same group member to be decisive in two consecutive periods, much higher than what would be expected if individuals would vote randomly. As a consequence, when counting how often an individual's vote was pivotal, for all groups we find that the most decisive group member was pivotal in at least 10 out of the 20 periods. Furthermore, in $20 \%$ of the groups the most decisive group member was pivotal in at least 15 periods, and in two groups a single group member was the median voter in all twenty periods.

Finally, we also find some pronounced heterogeneity in voting behavior across groups. This is indicated by Figure A3 in Appendix A, depicting the minimum, median, maximum proposal (averaged over all 20 periods) separately for each group. For example, we find the minimum proposals to range from as low as 6.0 to 51.3. Similarly, the median proposals range from 31.1 to 72.0, and the maximum proposals range from 46.3 to 96.4. Furthermore, while in the most homogeneous group the mean range of proposals amounts to 22.1, in the most heterogeneous group the dispersion of proposals is more than three times higher, amounting to 70.8 .

We now turn to the question of how the strategic uncertainty of being pivotal affects (proposed) conflict investments. To this end, we compare the distribution of proposals in the Democracy treatment with those decisions implemented by the dictators in the Restricted Dictatorship treatment. This is shown in the right panel of Figure 4. As can be seen, the

\footnotetext{
${ }^{13} \mathrm{~A}$ similar increase can be observed when using the standard deviation rather than the range of proposals within groups as a measure of dispersion. Here, we find a significant increase from 16.9 in periods 1-5 to 21.1 in periods 16-20 (Signrank test, $p=0.021$ ).

${ }^{14}$ In our tests we use clustering at the group level to correct for the fact that observations within groups are not independent.
} 
CDF's overlap considerably, indicating that both treatments are not only comparable with regard to implemented aggregate investments (see Section 4.1), but also with regard to individual proposals/investments. ${ }^{15}$ We hence find no evidence that strategic uncertainty with regard to whether one's own (proposed) investment is pivotal or not has any systematic effect on behavior. We summarize these findings in our third result.

Result 3: Despite the different nature of the democracy and the restricted dictatorship, conflict investments are remarkably similar across these two institution, both at the aggregate as well as the individual level.

\section{$5 \quad$ Endogenous selection of institutions}

So far, we have analyzed how conflict behavior differs across institutions when these are assigned exogenously. In the following, we turn to the results of the second part of our experiment, in which subjects were given the opportunity to adopt institutions endogenously. We start by describing the voting behavior at the beginning of part 2, where, using approval voting, individuals were asked to state for each of the four institutions whether they approve this institution or not. We then describe the conflict behavior in the newly formed groups.

\section{$5.1 \quad$ Approval voting}

The voting results are summarized in Table 3. The first column lists the number of supported institutions, ranging from 0 (no institution approved) to 4 (all institutions approved). As can be seen in the second column, the majority of subjects (60\%) approved two out of the four institutions and rejected the other half. A further $27 \%$ of subjects approved only one institution, and another $10 \%$ approved three institution. The remaining $3 \%$ of the subjects approved all institutions, indicating that they were indifferent between all options. The last four columns display the fraction of subjects supporting each of the four institutions conditional on having supported one, two, three or four institutions. The last row shows the total support for each institution, averaged over all subjects. The results

\footnotetext{
${ }^{15}$ The two treatments are further similar with regard to the volatility of investments, both within groups as well as within individuals. That is, in the Democracy treatment groups change their investment level (in absolute terms) from one period to another by 12.0 units on average, compared to 14.9 in the Restricted Dictatorship treatment (Mann-Whitney $\mathrm{U}$ test, $p=0.663$ ). Likewise, when comparing how much an individual changes her (proposed) investments across all twenty periods, we find a similar level of variability in both treatments. The average standard deviation of proposed investment levels amounts to 18.9 in the Democracy, compared to 17.4 when considering implemented investments by the restricted dictator (Mann-Whitney U test, $p=0.552$ ).
} 


\begin{tabular}{cccccc}
\hline \multirow{2}{*}{$\begin{array}{c}\text { Number of } \\
\text { supported } \\
\text { institutions }\end{array}$} & $N(\%)$ & AUT & DEM & DIC & RDIC \\
\cline { 3 - 5 } & $0(0 \%)$ & 0.00 & 0.00 & 0.00 & 0.00 \\
1 & $97(27 \%)$ & 0.47 & 0.33 & 0.08 & 0.11 \\
2 & $211(60 \%)$ & 0.55 & 0.83 & 0.13 & 0.49 \\
3 & $36(10 \%)$ & 0.89 & 0.97 & 0.33 & 0.81 \\
4 & $10(3 \%)$ & 1.00 & 1.00 & 1.00 & 1.00 \\
\hline Total & $354(100 \%)$ & 0.58 & 0.71 & 0.16 & 0.43 \\
\hline
\end{tabular}

Table 3: Approval of institutions

reveal that the Democracy is by far the most popular institution, being approved by $71 \%$ of all subjects. The second most favored institution is the Autonomy (58\%), followed by the the Restricted Dictatorship (43\%) and the Dictatorship (16\%). The differences in support across institutions are all highly statistically significant (Signrank tests, all pairwise comparisons $p<0.002)$. This pattern holds for all subjects, except the ones that only support one institution. Among the latter, the Autonomy is the most popular (47\%), followed by the Democracy (33\%) and the Restricted Dictatorship (11\%).

At the individual level, we find all but one out of the $2^{4}=16$ possible voting patterns (the only pattern that we do not observe is the one in which none of the four institution is supported). Figure 5 depicts the relative frequency of the five most popular voting patterns. The most frequent voting pattern (24.9\%) supports the autonomy and the democracy, but rejects the two types of dictatorship. In the second most frequent voting pattern (22.6\%), subjects support the democracy and the restricted dictatorship. On rank three, four, and five, we find voting patterns that support only the autonomy (13.0\%), only the democracy (9.0\%), and all institutions but the discriminatory dictatorship (6.8\%). Overall, these voting patterns account for $76 \%$ of all observations. The remaining voting patterns all occurred in less than five percent of the cases (see Table A2 in the appendix for a full description of all voting patterns).

Importantly, these results do not depend on the type of institution subjects experienced in the first part of the experiment. That is, we find no evidence that individuals are more or less likely to vote for a particular institution if they have already gained experience in that institution. Support for this comes from Table 4, summarizing the voting behavior by treatment. As can be seen, the support for each of the four different institutions is remarkably similar across treatments, with none of the differences reaching statistical significance $\left(\chi^{2}-\right.$ test, all $p>0.178)$. The past institution further has no impact on the number of institutions 


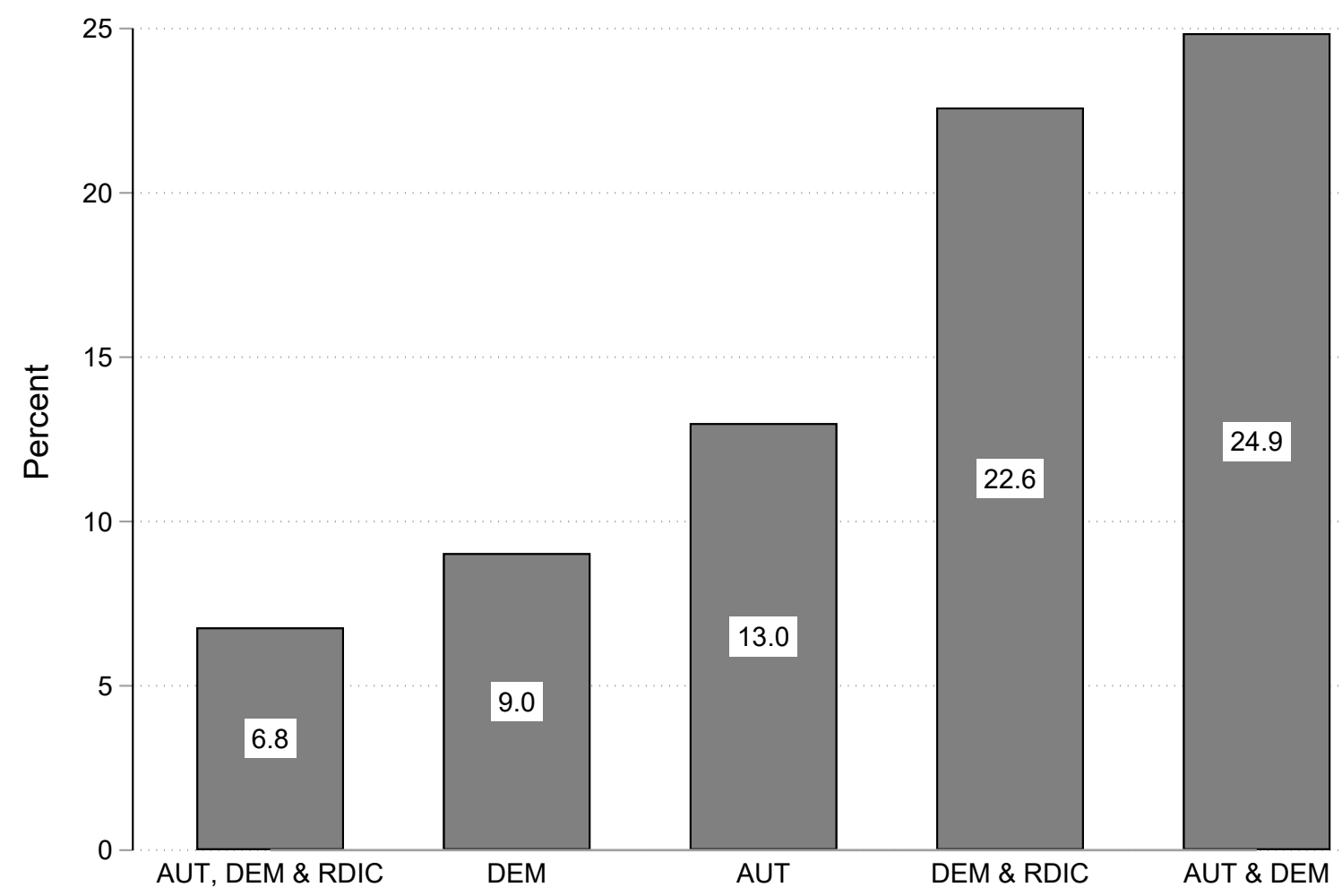

Figure 5: Five most frequent voting patterns

that are approved, as the numbers in the second column reveal. Interestingly, voting behavior also does not differ between subjects who in part 1 of the experiment played either as dictators or passive players under one of the dictatorship regimes (see Table A3 in Appendix A). Regression analyses further reveal that voting behavior is not affected by how well subjects performed in part 1 of the experiment. Specifically, for none of the four treatments we find that average payoffs in part 1 have any effect on the likelihood of supporting any of the four institutions (see Table A4 in Appendix A). Overall, these results suggest that there are very little spillover effects from subjects' experience in part 1 to their voting behavior at the beginning of part $2 .{ }^{16}$

What can explain these voting patterns? First of all, subjects might vote for a particular institution for strategic reasons. For example, when considering the theoretical predictions

\footnotetext{
${ }^{16}$ In the appendix, we report additional exploratory analyses investigating the role of demographics (gender, age) the field of studies, political attitudes, and risk preferences on voting behavior. The regression results are reported in Table A5. The results show that females are more (less) likely than men to support the Democracy (Dictatorship). Older participants are somewhat less likely so support the Democracy and the Restricted Dictatorship. For self-reported political attitudes we find that more conservative participants are more (less) likely to support the Autonomy (Restricted Dictatorship). Self-reported risk attitudes as well as the field of studies, in contrast, have no discernable effect on voting behavior.
} 


\begin{tabular}{lccccc}
\hline \multirow{2}{*}{ Institution Part 1 } & \multirow{2}{*}{$\begin{array}{c}\text { Mean number } \\
\text { of approvals }\end{array}$} & AUT & DEM & DIC & RDIC \\
\cline { 3 - 6 } & 1.88 & 0.52 & 0.77 & 0.12 & 0.46 \\
\hline Autonomy & 1.91 & 0.63 & 0.69 & 0.17 & 0.42 \\
Democracy & 1.78 & 0.51 & 0.68 & 0.16 & 0.43 \\
Dictator & 1.97 & 0.63 & 0.71 & 0.21 & 0.41 \\
Restricted Dictatorship & $p=0.393$ & $p=0.178$ & $p=0.510$ & $p=0.432$ & $p=0.907$ \\
\hline$\chi^{2}$-tests & & & & & \\
\hline
\end{tabular}

Table 4: Approval of institutions by treatment in part 1

for symmetric contests (between two groups of the same institution) as discussed in Section 3 (see Table 1), it is clear that the autonomy leads to the highest expected payoffs as investment levels are predicted to be the lowest. In particular, the predicted expected payoffs for an individual competing under the autonomy institution are 141.67, compared to 125 under the democracy and the restricted dictatorship. In the dictatorship, expected payoffs depend on the randomly assigned role, amounting to 150 for dictators and 50 for the passive group members. Given our group size of $n=3$, the average expected payoff under the dictatorship thus amounts to 83.33 .

These predictions change, of course, when considering asymmetric conflicts. Recall that in part 2 of our experiment groups were paired at random and, hence, conflicts between two groups who adopted different institutions could emerge. As a result, when considering which institution to vote for, subjects not only faced uncertainty with regard to the own group members' voting behavior, but also with regard to which institution the other group would adopt. In the following, we discuss how the different institutions are predicted to perform under the various possible asymmetric conflict that could arise (see Appendix B for a full description).

Recall that for the autonomy institution, the predicted group investment in symmetric contests is equal to 25 , the winning probability is equal to 0.5 , and the expected individual payoffs are equal 125. Relative to this case, the incentives to invest into the conflict decrease when competing against any of the other institutions. The intuition for this is similar to the discouragement effect arising in uneven contests between groups or players of different abilities (see e.g., Fonseca, 2009). Given that democratic and dictatorship groups are predicted to invest more than autonomy groups, for the latter the marginal incentives to invest into the conflict are lower when competing against a group of a different institution rather than when both groups are autonomies. For example, when competing against a group governed by a restricted dictatorship, the latter is predicted to invest a total of 56.25 , while the autonomy 
is predicted to invest only 18.75. As a consequence, the probability of winning the contest for the autonomy (restricted dictatorship) is 0.25 (0.75), and the expected payoffs amount to 106.25 (156.25). When competing against a group which adopted the dictatorship, the prospects for the autonomy are even more grim. Since a selfish dictator will always invest the whole endowment of his two group members, the predicted investment level amounts to 200, at a minimum. At such high investment levels of the other group, the marginal incentives to invest into the conflict for individuals in the autonomy are lower than the marginal costs, and hence predicted investment levels are equal to zero. As a consequence, the probability of winning the conflict is equal to zero, and the expected payoffs are equal to the initial endowment of 100. Members of the dictatorship, in contrast, benefit from having a weaker opponent compared to the symmetric case. Given that the dictatorship group will win the conflict with certainty, the expected payoffs for the dictator and the other two group members amount to 200 and 100, respectively. On average, the dictatorship thus yields a payoff of 133.33 .

Similar effects are obtained when considering the other possible asymmetric contests. For example, when a dictatorship competes against a restricted dictatorship, the latter is predicted to invest less than in the symmetric case (44.95 vs. 75 ), as the former competes more aggressively (as before, dictators are predicted to invest a total of 200). Hence, as it is the case for the autonomy, the restricted dictator gets discouraged by the high investments of the discriminatory dictator. The resulting winning probabilities are equal to 0.18 and 0.82 , leading to expected payoffs of 103.02 and 115.33 (dictator: 182, non-dictators: 82) for the restricted dictatorship and the dictatorship, respectively (compare Table B1 in Appendix B.

In sum, depending on the participants' beliefs about the voting behavior of the other players and the resulting probabilities of being matched with a group of a certain type, some institutions might have better prospects than others. Besides these purely strategic considerations, participants might also consider other aspects when deciding on which institution to vote for. For example, the most common voting pattern of only approving the autonomy and the democracy (compare Figure 5) can also be interpreted as subjects exhibiting a strong preference for self-determination, as these are the only two institutions in which all group members can decide on their individual investments. Similarly, the second most prevalent voting pattern - approval of only the democracy and the restricted dictatorship - is consistent with the idea of subjects expressing an aversion against inequality, as these are the only two institutions in which payoff equality within groups is guaranteed. While with our data we cannot determine the relative importance of these factors compared to the strategic motivations as discussed above, given the ample of evidence about importance of self-determination and inequity aversion for people's behavior in other contexts (e.g., Rawls, 
1971; Feinberg, 1978; Young, 1982; Ryan and Deci, 2000; Sobel, 2005; Fehr and Schmidt, 2006; Cooper and Kagel, 2016), it is likely that these motivations influence subjects' decisions also in our context. We summarize these findings in our fourth result.

Result 4: Giving autonomy to all group members and ruling out inequality within groups are both important features in determining the attractiveness of institutions in group conflict.

\subsection{Conflict behavior in endogenously selected institutions}

As a result of these voting patterns, 36 out of the 118 newly formed groups $(31 \%)$ implemented the autonomy institution, 58 (49\%) implemented the democracy, 2 (2\%) adopted the dictatorship, and $22(19 \%)$ implemented the restricted dictatorship. Groups were then randomly cross-matched into conflict pairs. As a consequence, both symmetric contests among two groups with the same institution as well as asymmetric contests between two groups that adopted different institutions emerged. In total, we have 18 symmetric contests (AUT-AUT: $n=3$, DEM-DEM: $n=13$, RDIC-RDIC: $n=2$ ) and 41 asymmetric contests (AUT-DEM: $n=22$, DEM-RDIC: $n=10$, AUT-RDIC: $n=7$, AUT-DIC: $n=1$, and DIC-RDIC: $n=1)$.

Figure 6 summarizes the conflict behavior in this newly formed groups. It shows, averaged over all twenty rounds, the mean group investments for each combination of institutions in the own and the opponent's group (except for the two dictatorship groups, which are omitted because of the insufficient number of observations). The first set of bars display the average group investments made by groups who adopted the autonomy institution. The second and third set of bars show conflict investments for groups who adopted a democracy or a restricted dictatorship, respectively. Within each set, the first bar shows conflict investments for the case in which the opponent's institution was an autonomy, while the second and third show conflict investments in case the other group adopted a democracy and restricted dictatorship, respectively. As a benchmark, the horizontal dashed lines indicate the average conflict investments from the first part of the experiment, in which institutions were assigned exogenously. Note that these benchmarks are only available for the symmetric cases, in which the own and the opponent's institution was the same.

Several interesting patterns emerge from this figure. First, we observe that the own institution has a significant impact on the level of conflict. In line with the results from part 1 , we find that the autonomy institution leads to the lowest conflict investments. Averaged over all opponents' types, total group investments amount to 71.3, which is much lower 


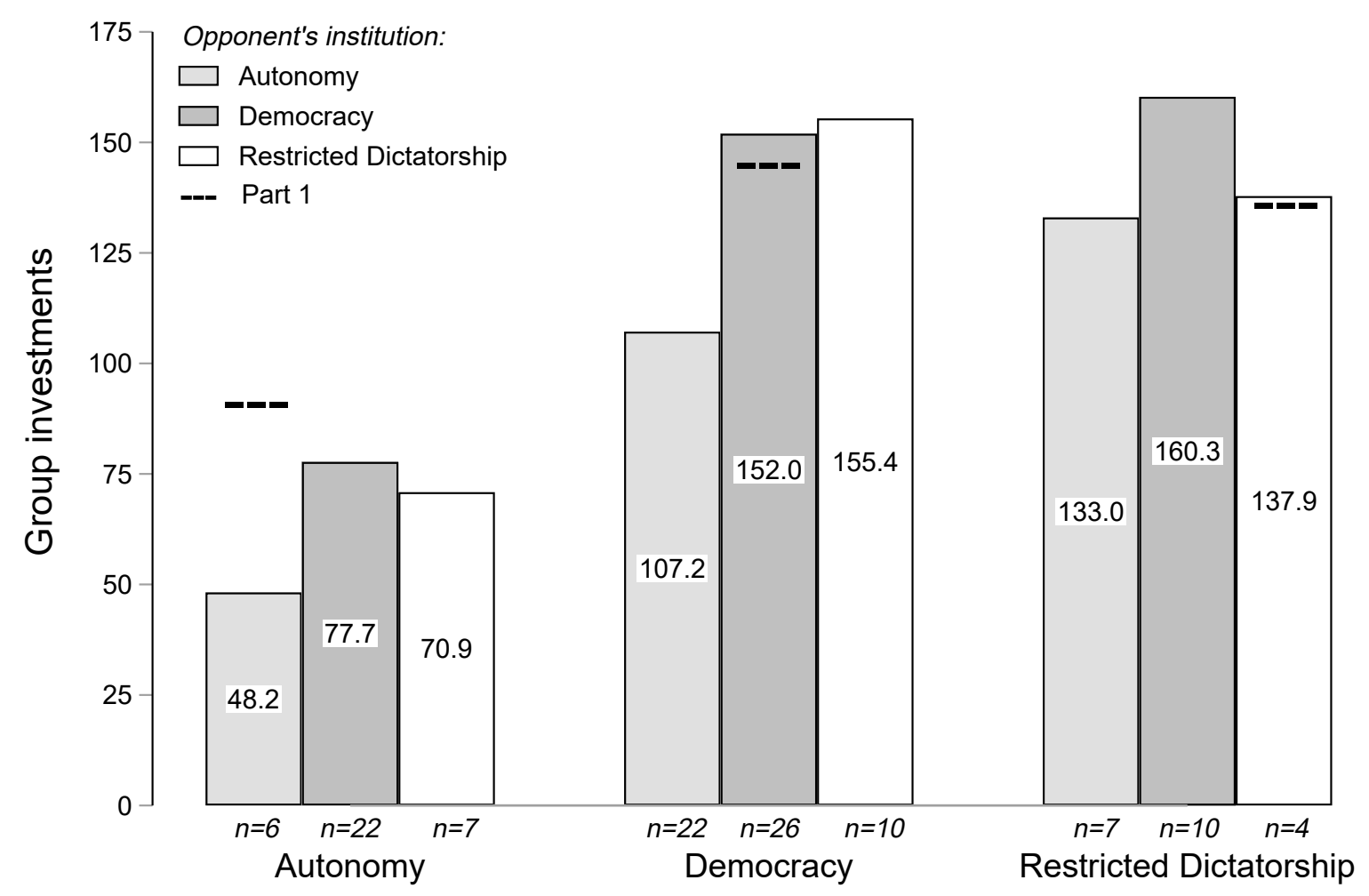

Figure 6: Conflict investments by groups in part 2, separated by the own and the opponent's institution. Number of groups are on the $x$-axis.

than the investments observed under the democracy (135.6) and the restricted dictatorship (146.9). Second, we find that conflict investments also crucially depend on the opponent's institution. In particular, holding constant the own institution, group investments are always lowest in case the other group is ruled by an autonomy. On average, groups invest a total of 102.2 tokens if the opponent's group is an autonomy, compared to 125.2 if it is a democracy and 123.9 if it is a restricted dictatorship.

To test the significance of these results, we run multilevel linear mixed-effects regressions that take into account the inter-dependency of observations (repeated observations of individuals that are nested within a contest of two competing groups). As the dependent variable we use an individual's conflict investment. As explanatory variables we use indicator variables for the different institutions in the own and the opponent's group. The results, which are shown in Table 5, confirm the findings from above. Groups who adopt the autonomy as an institution invest significantly less into conflict than groups who adopt the democracy (our baseline category). No significant differences are observed, in contrast, between democracies and restricted dictatorships. The same pattern holds for the institution of the 
Table 5: Conflict investments by own and opponent's institution

\begin{tabular}{lccc}
\hline & $(1)$ & $(2)$ & $(3)$ \\
\hline Own institution: & & & \\
AUT (d) & $(3.270)$ & $(3.246)$ & $(3.703)$ \\
& 3.220 & 3.502 & 2.938 \\
RDIC (d) & $(3.752)$ & $(3.810)$ & $(4.222)$ \\
& & & \\
Other's institution: & & & \\
AUT (d) & $-12.931^{* * *}$ & $-11.480 * * *$ & $-14.389^{* * *}$ \\
& $(3.297)$ & $(3.285)$ & $(3.729)$ \\
RDIC (d) & -1.582 & 0.685 & -3.819 \\
& $(3.641)$ & $(3.645)$ & $(4.117)$ \\
Constant & $50.370^{* * *}$ & $49.104^{* * *}$ & $51.634^{* * *}$ \\
\hline Observations & $(3.007)$ & $(2.957)$ & $(3.407)$ \\
\hline Notes: Mr & 6000 & 3000 & 3000 \\
\hline
\end{tabular}

Notes: Multilevel linear mixed-effects model with random intercepts at the contest, group, and individual level. Model (1) uses data from all periods. Model (2) uses data from periods 21 - 30, while model (3) uses data from periods 31 - 40. Numbers in parentheses indicate robust standard errors. Significance levels $* p<0.10, * *$ $p<0.05,{ }^{* * *} p<0.01$.

opponent: whenever the other group is an autonomy conflict investments significantly decrease, while there is no difference between democracies and restricted dictatorships. When comparing the relative magnitude of these effects, it seems that the own institution has a stronger impact on an individual's investment decision than the opponent's institution, at least for the autonomy.

These results are very robust over time. While model (1) reports the results using data from all periods, in model (2) we only use data from the first ten periods, and in model (3) we only use data from the last ten periods. As can be seen, the results are very similar across models indicating that learning and experience effects do not interfere with our overall results (see also Figure A4 in Appendix A).

Next, we investigate whether adopting an institution endogenously leads to systematically different conflict behavior compared to when the same institution is exposed exogenously. 
To this end, we compare the investment levels across the first and the second part of the experiment. ${ }^{17}$ Since we find that the opponent's institution significantly affects conflict investments, in order to have a clean comparison we only use data from the symmetric contests as shown by the first, the fifth, and the last bar of Figure 6 .

For the democracy and the restricted dictatorship, we find that conflict investments are very similar to, and not significantly different from, the levels observed in the first part of the experiment (democracy: 146.7 vs. 52.0; restricted dictatorship: 138.9 vs. 137.9; Signrank tests, both $p>0.439)$. For the autonomy institution, in contrast, we observe significantly lower investments compared to part 1 (48.2 vs. 94.4; Signrank test, $p=0.027$ ). While this difference could be interpreted as an "endogenous adoption effect", we believe that this is not the case for the following two reasons. First, given the absence of any systematic endogenous adoption effect for the other two institutions, it is not clear why such an effect should only be present for a particular institutions. Second and more importantly, the observed patterns in part 2 can be well explained by a continuation of the time trends as observed in part 1. In particular, while in the Democracy and the Restricted Dictatorship treatment we observed constant investment levels across periods, in the Autonomy treatment we found a significant downward trend of investments over time. In fact, while group investments under the autonomy in part 1 decrease from 114.0 in period 1 to 62.3 in period 20, in the first period of part 2 (period 21) they start at 59.3 and further decrease to 36.8 in period 40 . As such, these results suggest that conflict behavior is quite consistent across the two parts. We summarize these findings in our fifth result:

Result 5a: In asymmetric conflicts, the intensity of conflict depends on the institution of both the own group as well as the opponent's group.

Result 5b: Institutions have a similar effect on conflict investments irrespectively of whether they are imposed exogenously or adopted endogenously.

\section{Discussion and Conclusion}

Conflicts between groups are are ubiquitous in nature and exist at all levels in human society, ranging from wars between countries to rent-seeking activities within and across

\footnotetext{
${ }^{17}$ We note that since we did not counterbalance the order in which subjects played the two parts, experience effects could blur our comparison between exogenously and endogenously adopted institutions. We believe, however, that such experience effects play only a minor role in our context, if at all. Support for this comes from regression analyses testing for potential experience effects from part 1 to behavior in part 2. We find little evidence for such spillover effects. That is, we find that neither the institution that participants experienced in part 1, nor their performance in that institution has any effect on subjects' conflict investments in part 2 (see Table A6 in Appendix A).
} 
organizations. In this paper we study the importance of institutions on the development of conflict. In particular, we investigate how different types of governance structures within groups, affect the level of conflict between groups.

Our results reveal that the way groups are structured has a significant impact on the degree to which they engage into conflict. Relative to the situation in which individuals can decide completely autonomously on their level of conflict investment, conflict significantly intensifies when investment levels are determined by voting or by a single group member. This result holds for situations in which the institution is assigned exogenously, as well as when it is adopted endogenously. Furthermore, we find that the political institution not only affects behavior within the own group, but also matters for the rivaling party. In particular, our results reveal that in asymmetric contests groups strategically adjust their conflict investments to the institution of the opponent group. Surprisingly, in none of our settings we find that democratic structures within groups lead to less conflict compared to more autocratic regimes. Despite the lack of a strong difference between these different types of institutions with regard to the level of conflict and social efficiency, we find that individuals have a strong preference for adopting democratic structures, as it guarantees them participation in the decision process and protects them from exploitation by others.

Our paper contributes to the long-lasting discussion about the importance of institutions for economic performance (see e.g., Acemoglu et al., 2005). With regard to conflict, empirical evidence suggests that democratic countries tend to be more peaceful than non-democratic ones (e.g., Russett, 1993). Yet, up to now, it has been unclear whether this relationship is causal, as most previous research has relied on observational data. The problem with these naturally occurring conflicts is that the involved parties typically differ along a variety of dimensions, and institutions within theses groups have emerged endogenously, rendering identification difficult. To the best of our knowledge, here we provide the first clean evidence on the role of political institutions on the level of conflict. While our results can be interpreted as evidence that implementing democratic structures per se have no strong impact on the degree of conflict, a few cautionary notes are warranted. First of all, our results should not been seen as evidence against "democratic peace theory", but rather as providing important insights into some of the underlying mechanisms. In particular, our results suggest that giving people the right to vote is not the main reason for why democracies seem to be more peaceful than other countries. Second, while the advantage of the experimental methodology is to ease causal inference, naturally this comes at the cost of realism. That is, in order to isolate specific mechanisms, in experiments one has to abstract from many important aspects that might affect behavior outside the laboratory. Here, we looked at a very specific (and simplified) version of democracy that enforced participation and did not involve any 
elected policy makers. Furthermore, the dictators in our experiment were randomly selected participants, rather than a self-selected group of individuals that strive for power. This can explain, for example, why in our experiment we find a relatively low level of discrimination and exploitation of others, in contrast to what has been observed in many dictatorships across the globe. While these shortcomings do not invalidate our findings, we believe that extending our setup to more complex (and realistic) situations is a promising avenue for future research.

Our paper further contributes to the growing economic literature on the determinants of group conflicts (Sheremeta, 2018), which so far, however, has left the role of political institutions rather unexplored. Interestingly, in contrast to previous research on collective action that has found voting to increase cooperation and social efficiency (e.g., Walker et al., 2000; Bernard et al., 2013; Hauser et al., 2014), here we find that voting leads to lower social efficiency compared to the situation in which individuals can decide autonomously. While at first this might seem surprising, it is in line with previous evidence showing that institutions that have proven to be effective in some settings, might have detrimental effects in the context of conflict. Specifically, while in collective action problems communication and punishment typically lead to higher social efficiency (Ostrom et al., 1992; Fehr and Gächter, 2000; Gächter and Renner, 2003; Balliet, 2010), in group contests they tend to have the opposite effect (Sutter and Strassmair, 2009; Abbink et al., 2010; Leibbrandt and Sääksvuori, 2012; Cason et al., 2017). Relatedly, while previous research has shown that institutions often have a larger impact on behavior when implemented endogenously (Tyran and Feld, 2006; Kosfeld et al., 2009; Dal Bó et al., 2010; Sutter et al., 2010; Markussen et al., 2013; Sausgruber et al., 2019), in our context we find no evidence for such a "dividend of democracy". The general picture that emerges from these studies is that the efficacy of institutions in context-specific, and that alternative solution mechanisms are needed to mitigate conflict.

Finally, our paper may also have some policy implications as it relates to the long-standing literature in organizational and social psychology on the effects of leadership style on team performance. In their pioneering work, Lewin et al. (1939) classify three types of leadership that closely map into the different types of institutions considered her: Autocratic leadership, democratic leadership, and laissez-faire leadership. According to their definition, autocratic leaders will do whatever they think is necessary to achieve the goal, without consulting the subordinates; democratic leaders will actively involve the group members into the decisionmaking process, e.g., via discussion or voting; and laissez-faire style leaders will take a passive role and provide full freedom to the group members to decide for themselves. Our results that individuals prefer the democracy and autonomy over the dictatorship is consistent with 
previous findings showing that autocratic leadership styles can lead to a destabilization of groups (Van Vugt et al., 2004) and to lower overall satisfaction (e.g., Miller and Monge, 1986; Yukl, 1998). 


\section{References}

Abbink, K., J. Brandts, B. Herrmann, and H. Orzen (2010). Intergroup conflict and intragroup punishment in an experimental contest game. American Economic Review 100(1), $420-447$.

Acemoglu, D., S. Johnson, and J. A. Robinson (2005). Institutions as a fundamental cause of long-run growth. Handbook of economic growth 1, 385-472.

Adams, J. S. (1963). Towards an understanding of inequity. The Journal of Abnormal and Social Psychology 67(5), 422.

Aumann, R. (1959). Acceptable points in general cooperative n-person games, Volume 4. Princeton University Press.

Baik, K. H. (1993). Effort levels in contests: The public-good prize case. Economics Letters 41(4), 363-367.

Balliet, D. (2010). Communication and cooperation in social dilemmas: A meta-analytic review. Journal of Conflict Resolution 54(1), 39-57.

Bardhan, P. (2000). Irrigation and cooperation: An empirical analysis of 48 irrigation communities in south india. Economic Development and cultural change 48(4), 847-865.

Bartling, B., E. Fehr, and H. Herz (2014). The intrinsic value of decision rights. Econometrica 82(6), 2005-2039.

Bass, B. M. (2009). The Bass handbook of leadership: Theory, research, and managerial applications. New York: Free Press.

Bernard, M., A. Dreber, P. Strimling, and K. Eriksson (2013). The subgroup problem: When can binding voting on extractions from a common pool resource overcome the tragedy of the commons? Journal of Economic Behavior \& Organization 91, 122-130.

Bernheim, B. D., B. Peleg, and M. D. Whinston (1987). Coalition-proof nash equilibria i. concepts. Journal of Economic Theory 42(1), 1-12.

Bolton, G. E. and A. Ockenfels (2000). ERC - A theory of equity, reciprocity and competition. American Economic Review 100(1), 166-93.

Brams, S. and P. C. Fishburn (2007). Approval voting. Springer Science \& Business Media.

Brams, S. J. and P. C. Fishburn (1978). Approval voting. American Political Science Review 72(3), 831-847.

Cason, T. N., R. M. Sheremeta, and J. Zhang (2012). Communication and efficiency in competitive coordination games. Games and Economic Behavior 76 (1), 26-43.

Cason, T. N., R. M. Sheremeta, and J. Zhang (2017). Asymmetric and endogenous communication in competition between groups. Experimental Economics 20, 946-972. 
Christman, J. (2008). Autonomy in moral and political philosophy. Stanford encyclopedia of philosophy.

Cooper, D. J. and J. Kagel (2016). Other-regarding preferences. The Handbook of Experimental Economics 2, 217.

Dal Bó, P., A. Foster, and L. Putterman (2010). Institutions and behavior: Experimental evidence on the effects of democracy. American Economic Review 100(5), 2205-29.

De Mesquita, B. B., J. D. Morrow, R. M. Siverson, and A. Smith (1999). An institutional explanation of the democratic peace. American Political Science Review 93(4), 791-807.

Dohmen, T., A. Falk, D. Huffman, and U. Sunde (2010). Are risk aversion and impatience related to cognitive ability? American Economic Review 100(3), 1238-60.

Eisenkopf, G. (2014). The impact of management incentives in intergroup contests. European Economic Review 67, 42-61.

Fallucchi, F., E. Renner, and M. Sefton (2013). Information feedback and contest structure in rent-seeking games. European Economic Review 64, 223-240.

Fehr, E. and S. Gächter (2000). Cooperation and punishment in public goods experiments. American Economic Review 90(4), 980-994.

Fehr, E. and K. Schmidt (1999). A Theory of Fairness, Competition, and Cooperation. Quarterly Journal of Economics 114(3), 817-868.

Fehr, E. and K. M. Schmidt (2006). The economics of fairness, reciprocity and altruism experimental evidence and new theories. In S. Kolm and J. M. Ythier (Eds.), Handbook of the Economics of Giving, Altruism, and Reciprocity, Volume 1, pp. 615-691. Elsevier.

Feinberg, J. (1978). Freedom and behavior control. In Encyclopedia of Bioethics, pp. 93-100. Reich, Warren T.

Festinger, L. (1954). A theory of social comparison processes. Human Relations 7(2), 117140.

Fischbacher, U. (2007). z-tree: Zurich toolbox for ready-made economic experiments. Experimental Economics 10(2), 171-178.

Fonseca, M. A. (2009). An experimental investigation of asymmetric contests. International Journal of Industrial Organization 27(5), 582-591.

Gächter, S. and E. Renner (2003). Leading by example in the presence of free rider incentives.

Garfinkel, M. R. and S. Skaperdas (2007). Economics of conflict: An overview. Handbook of defense economics 2, 649-709.

Greiner, B. (2015). Subject pool recruitment procedures: organizing experiments with orsee. Journal of the Economic Science Association 1, 1-12. 
Gürtler, O. (2008). On sabotage in collective tournaments. Journal of Mathematical Economics $44(3-4), 383-393$.

Hardin, G. (1968). Tragedy of the commons. Science 162, 1243-1248.

Hauser, O. P., D. G. Rand, A. Peysakhovich, and M. A. Nowak (2014). Cooperating with the future. Nature 511(7508), 220-223.

Heine, F. and A. Riedl (2019). Let's (not) escalate this! intergroup leadership in a team contest. Working Paper.

Jackson, M. O. and M. Morelli (2007). Political bias and war. American Economic Review 97(4), 1353-1373.

Katz, E., S. Nitzan, and J. Rosenberg (1990). Rent-seeking for pure public goods. Public Choice 65(1), 49-60.

Konrad, K. A. (2009). Strategy and dynamics in contests. Oxford University Press.

Kosfeld, M., A. Okada, and A. Riedl (2009). Institution formation in public goods games. The American Economic Review 99(4), 1335-1355.

Laslier, J.-F. and M. R. Sanver (2010). Handbook on approval voting. Springer Science \& Business Media.

Laslier, J.-F. and K. Van der Straeten (2008). A live experiment on approval voting. Experimental Economics 11(1), 97-105.

Leibbrandt, A. and L. Sääksvuori (2012). Communication in intergroup conflicts. European Economic Review 56(6), 1136-1147.

Lewin, K., R. Lippitt, and R. K. White (1939). Patterns of aggressive behavior in experimentally created "social climates". The Journal of social psychology 10(2), 269-299.

Loewenstein, G. F., L. Thompson, and M. H. Bazerman (1989). Social utility and decision making in interpersonal contexts. Journal of Personality and Social Psychology 57(3), 426.

Maoz, Z. and B. Russett (1993). Normative and structural causes of democratic peace, 1946-1986. American Political Science Review 87(3), 624-638.

Markussen, T., L. Putterman, and J.-R. Tyran (2013). Self-organization for collective action: An experimental study of voting on sanction regimes. Review of Economic Studies 81 (1), $301-324$.

Mellizo, P., J. Carpenter, and P. H. Matthews (2014). Workplace democracy in the lab. Industrial Relations Journal 45(4), 313-328.

Miller, K. I. and P. R. Monge (1986). Participation, satisfaction, and productivity: A metaanalytic review. Academy of Management Journal 29(4), 727-753. 
Münster, J. (2009). Group contest success functions. Economic Theory 41(2), 345-357.

Olson, M. (1965). The Logic of Collective Action: Public Goods and the Theory of Groups. Harvard University Press.

Ostrom, E., R. Gardner, and J. Walker (1994). Rules, Games, and Common-Pool Resources. University of Michigan Press.

Ostrom, E., J. Walker, and R. Gardner (1992). Covenants with and without a sword: Selfgovernance is possible. American political science Review 86(2), 404-417.

Owen, J. M. (1994). How liberalism produces democratic peace. International security 19(2), $87-125$.

Ramsbotham, O., H. Miall, and T. Woodhouse (2011). Contemporary conflict resolution. Polity.

Rawls, J. (1971). A theory of justice. Harvard university press.

Russett, B. (1993). Grasping the democratic peace: Principles for a post-Cold War world. Princeton University Press.

Ryan, R. M. and E. L. Deci (2000). Self-determination theory and the facilitation of intrinsic motivation, social development, and well-being. American psychologist 55(1), 68.

Sausgruber, R., A. Sonntag, and J.-R. Tyran (2019). Disincentives from redistribution: Evidence on a dividend of democracy.

Sheremeta, R. M. (2018). Behavior in group contests: A review of experimental research. Journal of Economic Surveys 32(3), 683-704.

Sherif, M., O. J. Harvey, B. J. White, W. R. Hood, and C. W. Sherif (1961). Intergroup conflict and cooperation: The Robbers Cave experiment. Norman: University of Oklahoma.

Sobel, J. (2005). Interdependent preferences and reciprocity. Journal of Economic Literature $43(2), 392-436$.

Sutter, M., S. Haigner, and M. G. Kocher (2010). Choosing the carrot or the stick? endogenous institutional choice in social dilemma situations. The Review of Economic Studies $77(4), 1540-1566$.

Sutter, M. and C. Strassmair (2009). Communication, cooperation and collusion in team tournaments-an experimental study. Games and Economic Behavior 66(1), 506-525.

Tajfel, H. (1982). Social psychology of intergroup relations. Annual review of psychology $33(1), 1-39$.

Torgler, B. (2005). Tax morale and direct democracy. european Journal of Political economy $21(2), 525-531$. 
Tullock, G. (1967). The welfare costs of tariffs, monopolies, and theft. Economic Inquiry 5(3), 224-232.

Tullock, G. (1980). Efficient rent-seeking. In Toward a theory of the rent-seeking society. Texas A\&M University Press.

Tyran, J.-R. and L. P. Feld (2006). Achieving compliance when legal sanctions are nondeterrent. scandinavian Journal of Economics 108(1), 135-156.

Van Vugt, M., S. F. Jepson, C. M. Hart, and D. De Cremer (2004). Autocratic leadership in social dilemmas: A threat to group stability. Journal of experimental social psychology $40(1), 1-13$.

Walker, J. M., R. Gardner, A. Herr, and E. Ostrom (2000). Collective choice in the commons: Experimental results on proposed allocation rules and votes. The Economic Journal 110(460), 212-234.

Weber, R. J. (1995). Approval voting. Journal of Economic Perspectives 9(1), 39-49.

Young, R. (1982). The value of autonomy. The Philosophical Quarterly 32(126), 35-44.

Yukl, G. A. (1998). Leadership in organizations. Englewood Cliffs, NJ: Prentice Hall. 


\section{Appendix}

\section{A Additional Tables and Figures}

Table A1: Individual conflict investments by treatment

\begin{tabular}{|c|c|c|}
\hline & $(1)$ & $(2)$ \\
\hline $\operatorname{DEM}(\mathrm{d})$ & $\begin{array}{c}17.424^{* * *} \\
(4.942)\end{array}$ & $\begin{array}{c}13.747^{* * *} \\
(5.079)\end{array}$ \\
\hline $\mathrm{DIC}(\mathrm{d})$ & $\begin{array}{c}20.156^{* * *} \\
(4.942)\end{array}$ & $\begin{array}{c}14.016^{* * *} \\
(5.079)\end{array}$ \\
\hline $\operatorname{RDIC}(\mathrm{d})$ & $\begin{array}{c}14.826^{* * *} \\
(4.942)\end{array}$ & $\begin{array}{c}12.427^{* *} \\
(5.079)\end{array}$ \\
\hline Period & & $\begin{array}{c}-0.789 * * * \\
(0.080)\end{array}$ \\
\hline Period $\times$ DEM & & $\begin{array}{c}0.350^{* * *} \\
(0.111)\end{array}$ \\
\hline Period $\times$ DIC & & $\begin{array}{c}0.585^{* * *} \\
(0.111)\end{array}$ \\
\hline Period $\times$ RDIC & & $\begin{array}{c}0.228^{* *} \\
(0.111)\end{array}$ \\
\hline Constant & $\begin{array}{c}31.471^{* * *} \\
(3.554)\end{array}$ & $\begin{array}{c}39.752^{* * *} \\
(3.652)\end{array}$ \\
\hline Observations & 7080 & 7080 \\
\hline F-tests: & & \\
\hline $\mathrm{DEM}=\mathrm{DIC}$ & $p=0.593$ & $p=0.791$ \\
\hline $\mathrm{DEM}=\mathrm{RDIC}$ & $p=0.574$ & $p=0.957$ \\
\hline $\mathrm{DIC}=\mathrm{RDIC}$ & $p=0.272$ & $p=0.750$ \\
\hline
\end{tabular}

Notes: Multilevel linear mixed-effects model with random intercepts at the contest, group, and individual level. Numbers in parentheses indicate robust standard errors. Significance levels ${ }^{*} p<0.10,{ }^{* *} p<0.05,{ }^{* * *} p<0.01$. 
Table A2: Voting patterns (sorted by frequency of occurrence in decreasing order)

\begin{tabular}{|c|c|c|c|c|}
\hline$N(\%)$ & $\begin{array}{l}\text { Autonomy } \\
\text { (AUT) }\end{array}$ & $\begin{array}{c}\text { Democracy } \\
\quad(\mathrm{DEM})\end{array}$ & $\begin{array}{l}\text { Dictator } \\
\text { (DIC) }\end{array}$ & $\begin{array}{c}\text { Restricted } \\
\text { Dictatorship } \\
\text { (RDIC) }\end{array}$ \\
\hline $88(24.9 \%)$ & $\checkmark$ & $\checkmark$ & $\mathrm{x}$ & $\mathrm{x}$ \\
\hline $80(22.6 \%)$ & $\mathrm{x}$ & $\checkmark$ & $\mathrm{x}$ & $\checkmark$ \\
\hline $46(13.0 \%)$ & $\checkmark$ & $\mathrm{x}$ & $\mathrm{x}$ & $\mathrm{x}$ \\
\hline $32(9.0 \%)$ & $\mathrm{x}$ & $\checkmark$ & $\mathrm{x}$ & $\mathrm{x}$ \\
\hline $24(6.8 \%)$ & $\checkmark$ & $\checkmark$ & $\mathrm{x}$ & $\checkmark$ \\
\hline $15(4.2 \%)$ & $\checkmark$ & $\mathrm{x}$ & $\mathrm{x}$ & $\checkmark$ \\
\hline $13(3.7 \%)$ & $\checkmark$ & $\mathrm{x}$ & $\checkmark$ & $\mathrm{x}$ \\
\hline $11(3.1 \%)$ & $\mathrm{x}$ & $\mathrm{x}$ & $\mathrm{x}$ & $\checkmark$ \\
\hline $10(2.8 \%)$ & $\checkmark$ & $\checkmark$ & $\checkmark$ & $\checkmark$ \\
\hline $8(2.3 \%)$ & $\mathrm{x}$ & $\mathrm{x}$ & $\checkmark$ & $\mathrm{x}$ \\
\hline $8(2.3 \%)$ & $\mathrm{x}$ & $\mathrm{x}$ & $\checkmark$ & $\checkmark$ \\
\hline $7(2.0 \%)$ & $\checkmark$ & $\checkmark$ & $\checkmark$ & $\mathrm{x}$ \\
\hline $7(2.0 \%)$ & $\mathrm{x}$ & $\checkmark$ & $\checkmark$ & $\mathrm{x}$ \\
\hline $4(1.1 \%)$ & $\mathrm{x}$ & $\checkmark$ & $\checkmark$ & $\checkmark$ \\
\hline $1(0.3 \%)$ & $\checkmark$ & $\mathrm{x}$ & $\checkmark$ & $\checkmark$ \\
\hline $0(0 \%)$ & $\mathrm{x}$ & $\mathrm{x}$ & $\mathrm{x}$ & $\mathrm{x}$ \\
\hline
\end{tabular}

Notes: Checkmarks indicate that an institution was approved, and x's indicate that an institution was not approved. 
Table A3: Approval of institutions by experienced role in the dictatorship treatments in part 1

\begin{tabular}{|c|c|c|c|c|c|}
\hline \multirow{2}{*}{ Role Part 1} & \multirow{2}{*}{$\begin{array}{c}\text { Mean number } \\
\text { of approvals }\end{array}$} & \multicolumn{4}{|c|}{ Fraction support } \\
\hline & & AUT & DEM & $\mathrm{DIC}$ & RDIC \\
\hline \multicolumn{6}{|l|}{ Dictatorship } \\
\hline Dictators $(n=30)$ & 1.80 & 0.47 & 0.80 & 0.10 & 0.43 \\
\hline Non-dictators $(n=60)$ & 1.77 & 0.53 & 0.62 & 0.18 & 0.43 \\
\hline$\chi^{2}$-tests & $p=0.827$ & $p=0.551$ & $p=0.079$ & $p=0.304$ & $p=1.000$ \\
\hline \multicolumn{6}{|c|}{ Restricted Dictatorship } \\
\hline Dictators $(n=30)$ & 2.10 & 0.60 & 0.73 & 0.30 & 0.47 \\
\hline Non-dictators $(n=60)$ & 1.90 & 0.65 & 0.70 & 0.17 & 0.38 \\
\hline$\chi^{2}$-tests & $p=0.554$ & $p=0.643$ & $p=0.742$ & $p=0.144$ & $p=0.449$ \\
\hline
\end{tabular}


Table A4: Voting behavior depending on experience in part 1

\begin{tabular}{lcccc}
\hline \multirow{2}{*}{ Dependent variable: } & \multicolumn{4}{c}{ Institution supported (1 if yes, 0 otherwise) } \\
\cline { 2 - 5 } & AUT & DEM & DIC & RDIC \\
\hline DEM in part 1 (d) & 0.902 & -3.534 & 3.079 & 0.774 \\
& $(2.506)$ & $(2.815)$ & $(3.563)$ & $(2.476)$ \\
DIC in part 1 (d) & 2.358 & -2.618 & 0.047 & -1.247 \\
& $(1.860)$ & $(2.174)$ & $(2.806)$ & $(1.847)$ \\
RDIC in part 1 (d) & 3.325 & -2.305 & -0.031 & -2.411 \\
& $(2.048)$ & $(2.336)$ & $(2.922)$ & $(2.022)$ \\
Average payoff part 1 & 0.015 & -0.008 & 0.002 & -0.008 \\
Average payoff part 1 $\times$ DEM & $(0.014)$ & $(0.017)$ & $(0.021)$ & $(0.014)$ \\
& -0.002 & 0.029 & -0.026 & -0.011 \\
Average payoff part 1 $\times$ DIC & $(0.023)$ & $(0.026)$ & $(0.033)$ & $(0.023)$ \\
& -0.021 & 0.020 & 0.003 & 0.010 \\
Average payoff part 1 $\times$ RDIC & $(0.016)$ & $(0.019)$ & $(0.024)$ & $(0.016)$ \\
& -0.026 & 0.018 & 0.007 & 0.020 \\
Constant & $(0.018)$ & $(0.020)$ & $(0.025)$ & $(0.018)$ \\
& -1.686 & 2.156 & -2.277 & 0.837 \\
Observations & $(1.684)$ & $(2.010)$ & $(2.572)$ & $(1.669)$ \\
\hline
\end{tabular}

Notes: Logistic regressions. The dependent variable takes value 1 if the institution was supported and 0 otherwise. Numbers in parentheses indicate robust standard errors. Significance levels ${ }^{*} p<0.10,{ }^{* *}$ $p<0.05,{ }^{* * *} p<0.01$. 
Table A5: Determinants of voting behavior

\begin{tabular}{lcccc}
\hline Dependent variable: & \multicolumn{2}{c}{ Institution supported $(1$ if yes, 0 otherwise $)$} \\
\cline { 2 - 5 } & AUT & DEM & DIC & RDIC \\
\hline Female (d) & $0.410^{*}$ & $0.725^{* * *}$ & $-0.799^{* *}$ & 0.051 \\
Economics (d) & $(0.240)$ & $(0.267)$ & $(0.319)$ & $(0.240)$ \\
& 0.303 & -0.332 & 0.057 & -0.179 \\
Age & $(0.239)$ & $(0.270)$ & $(0.323)$ & $(0.242)$ \\
& 0.023 & $-0.073^{* *}$ & 0.028 & $-0.059^{* *}$ \\
Political attitudes & $(0.021)$ & $(0.029)$ & $(0.020)$ & $(0.028)$ \\
& $0.126^{* *}$ & -0.075 & 0.027 & $-0.119^{* *}$ \\
Risk & $(0.058)$ & $(0.060)$ & $(0.074)$ & $(0.059)$ \\
& 0.023 & 0.043 & 0.121 & -0.047 \\
Constant & $(0.051)$ & $(0.057)$ & $(0.082)$ & $(0.050)$ \\
\hline Observations & $-1.294^{*}$ & $2.559^{* * *}$ & $-2.746^{* * *}$ & $1.927^{* *}$ \\
\hline Notes: Logitic & $(0.664)$ & $(0.860)$ & $(0.833)$ & $(0.792)$ \\
\hline
\end{tabular}

Notes: Logistic regressions. The dependent variable takes value 1 if the institution was supported and 0 otherwise. Political attitudes were elicited on a scale from 0 (Left) to 10 (Right). Risk attitudes were elicited on a scale from 0 (not at all willing to take risks) to 10 (very willing to take risks) (Dohmen et al., 2010). Numbers in parentheses indicate robust standard errors. Significance levels $* p<0.10,{ }^{*} *$ $p<0.05,{ }^{* * *} p<0.01$. 
Table A6: Conflict investments depending on experience in part 1

\begin{tabular}{lccc}
\hline \multirow{2}{*}{ Dependent variable: } & \multicolumn{3}{c}{ Investments in part 2} \\
\cline { 2 - 4 } & AUT & DEM & RDIC \\
\hline DEM (d) & -38.003 & 10.894 & 5.703 \\
DIC (d) & $25.883)$ & $(9.506)$ & $(16.002)$ \\
& -2.956 & -0.208 & 9.515 \\
RDIC (d) & $(20.660)$ & $(7.569)$ & $(12.953)$ \\
& -13.204 & 3.707 & -6.012 \\
Payoff in part 1 & $(21.756)$ & $(8.283)$ & $(13.606)$ \\
& -0.190 & 0.001 & -0.001 \\
Payoff in part $1 \times$ DEM & $(0.146)$ & $(0.033)$ & $(0.070)$ \\
Payoff in part $1 \times$ DIC & 0.333 & -0.005 & -0.008 \\
& $(0.221)$ & $(0.061)$ & $(0.124)$ \\
Payoff in part $1 \times$ RDIC & 0.010 & -0.004 & 0.002 \\
Constant & $(0.166)$ & $(0.039)$ & $(0.080)$ \\
& 0.172 & -0.004 & -0.004 \\
Observations & $(0.176)$ & $(0.050)$ & $(0.087)$ \\
\hline & $44.974^{* *}$ & $41.354^{* * *}$ & $46.959^{* * *}$ \\
& $(18.654)$ & $(5.892)$ & $(10.484)$ \\
\hline
\end{tabular}

Notes: Multilevel linear mixed-effects model with random intercepts at the contest, group, and individual level. Numbers in parentheses indicate robust standard errors. Significance levels ${ }^{*} p<0.10,{ }^{* *} p<0.05,{ }^{* * *} p<0.01$. 
Figure A1: Distribution of total group investments in part 1 for each of the four institutions.

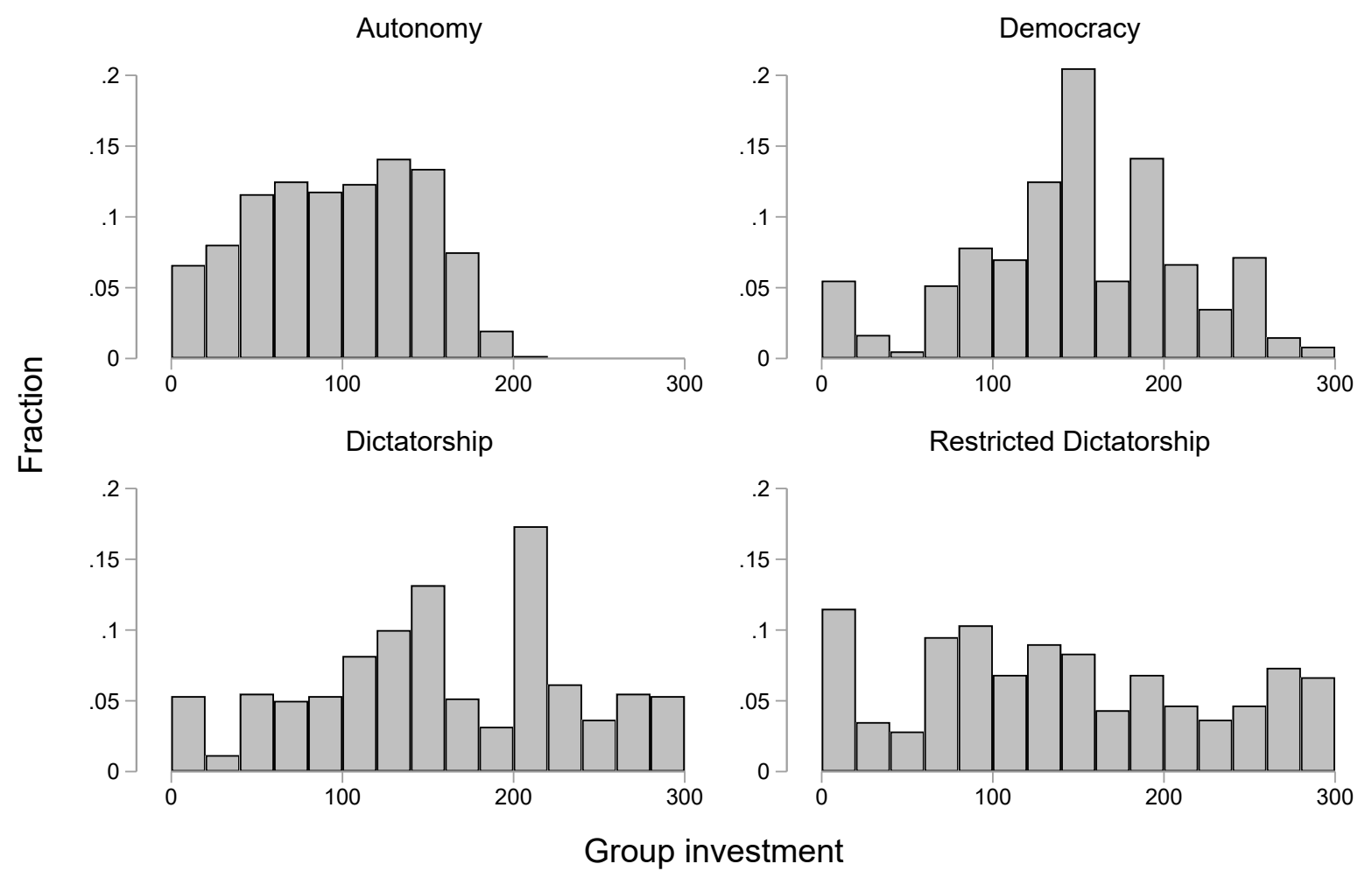


Figure A2: Minimum, median, and maximum proposed investment level in the Democracy treatment over time.

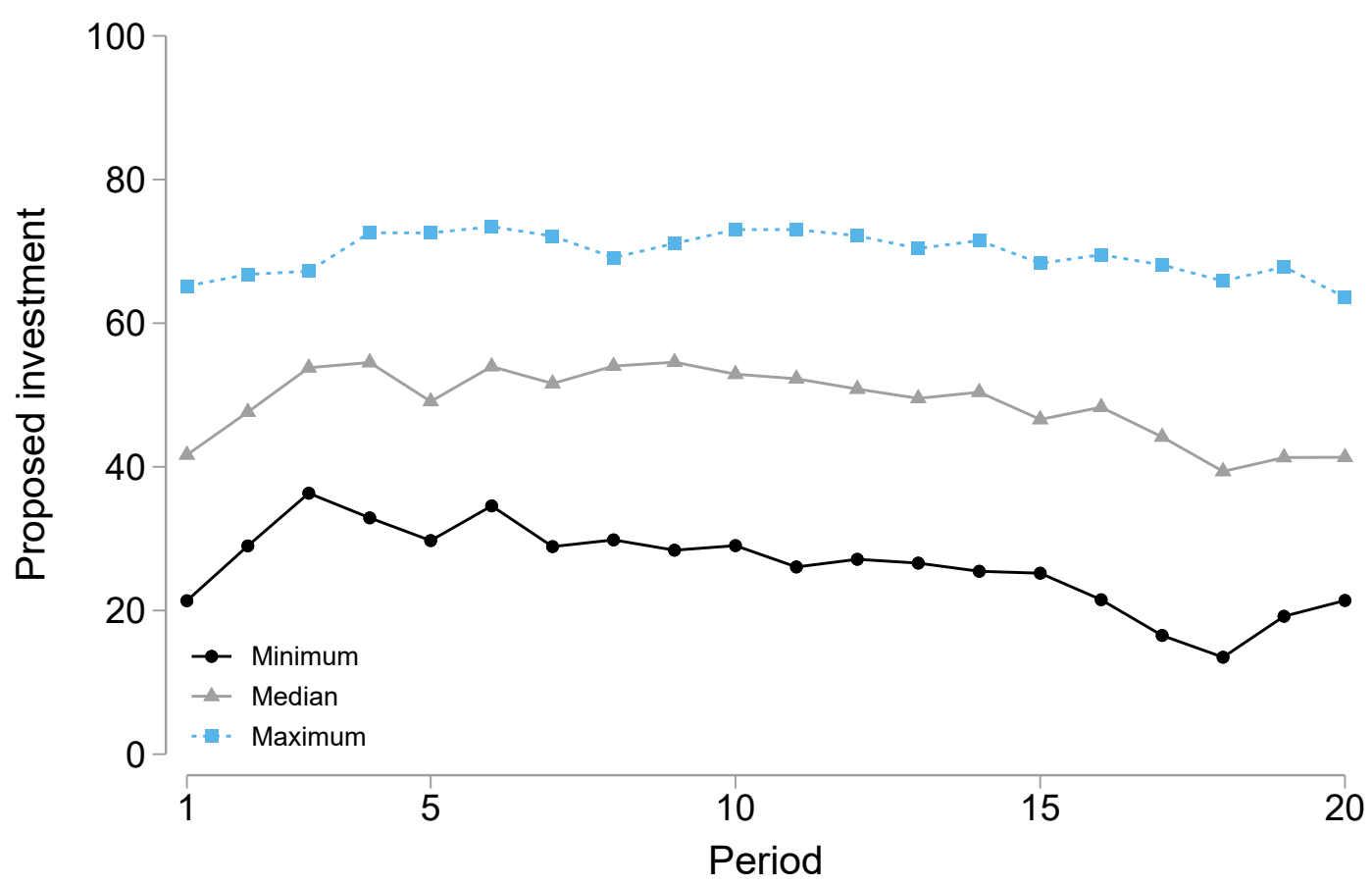


Figure A3: Heterogeneity across groups in the Democracy treatment.

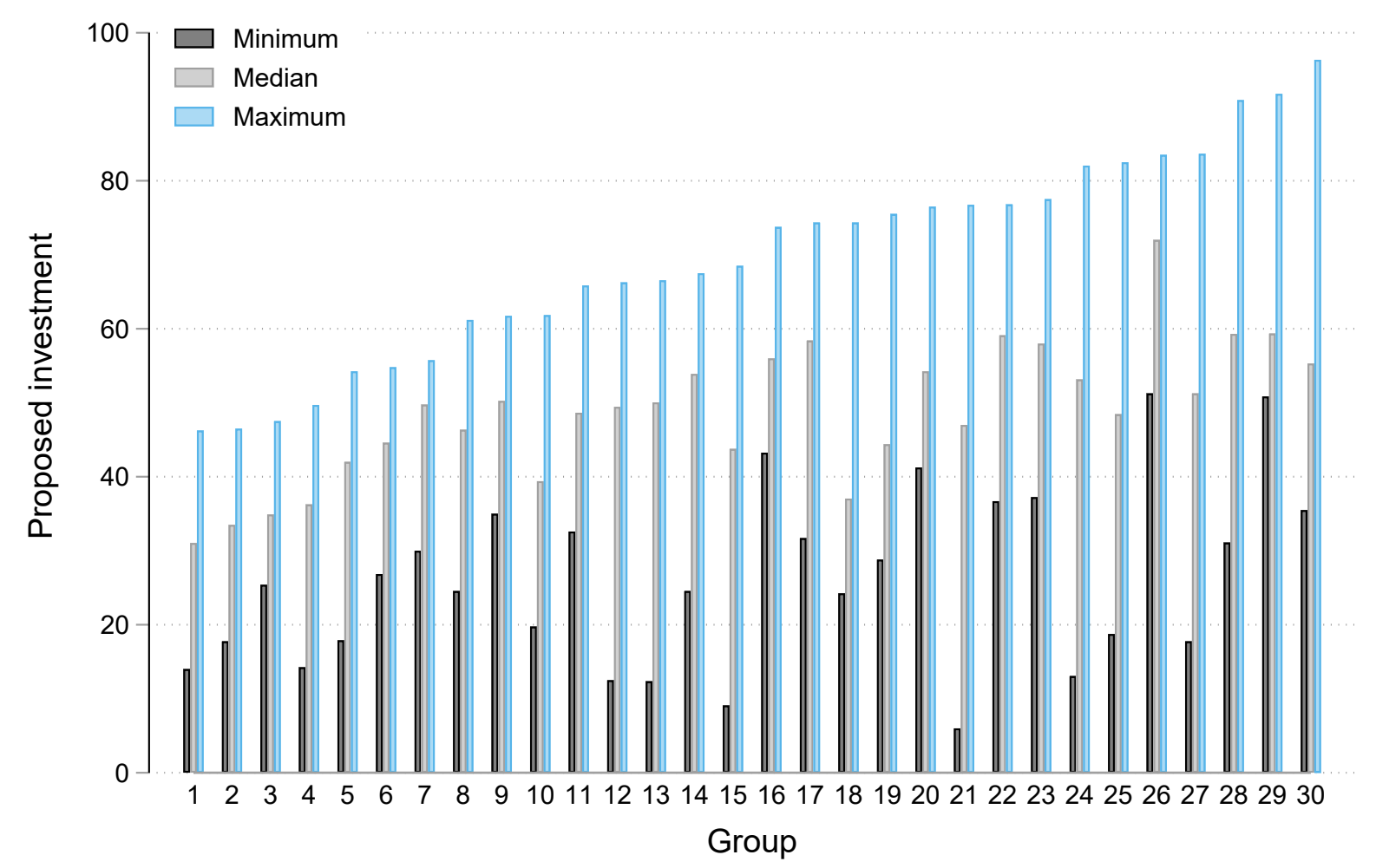

Notes: The bars show, for each group, the minimum, median, and maximum proposed investment level, averaged over all twenty periods. Groups are sorted from the lowest to the highest maximum proposal. 
Figure A4: Conflict investments in part 2 by own and other's institution.

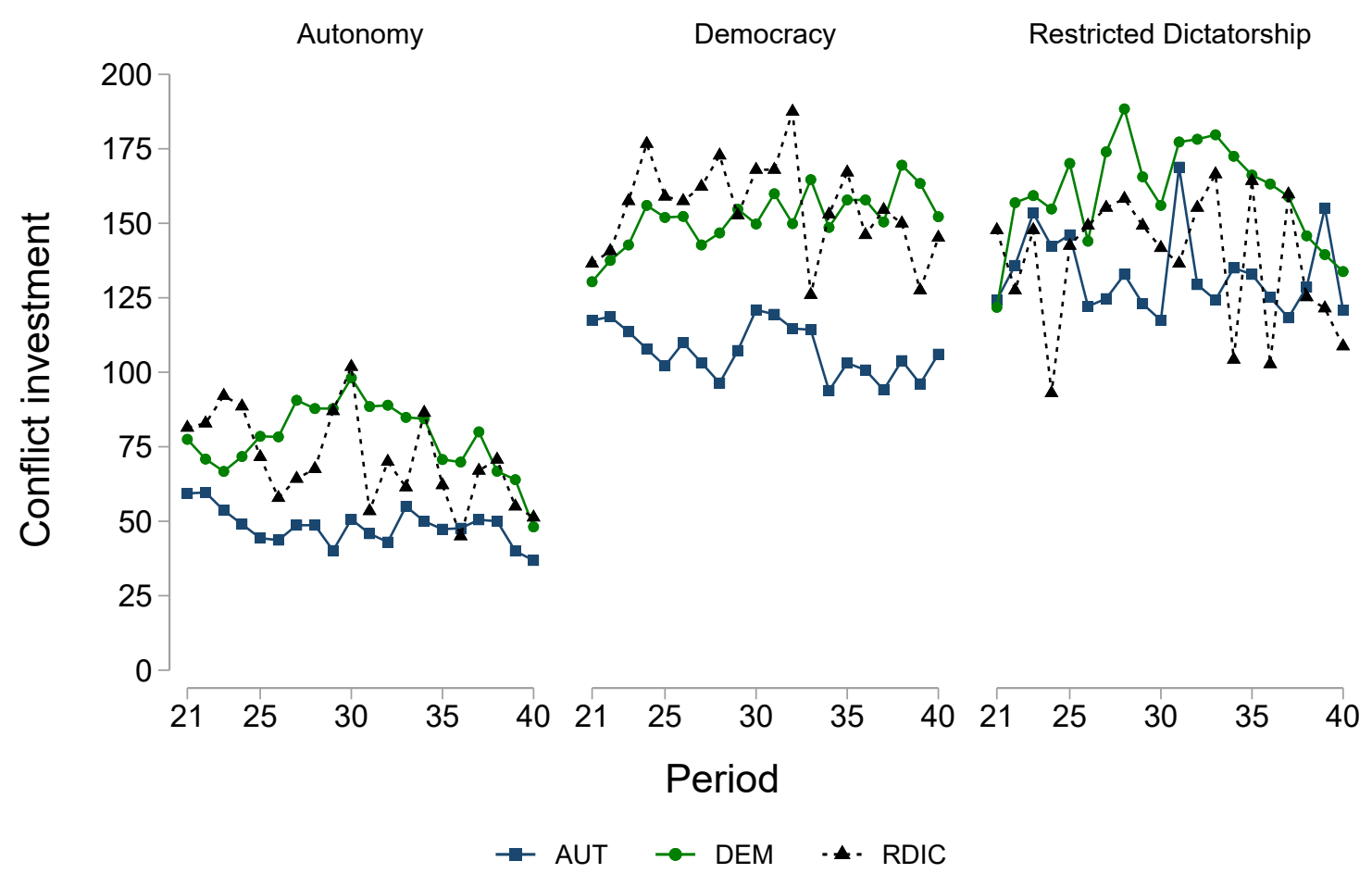




\section{B Theoretical Considerations}

The basic decision situation is an adaption of the classical Tullock contest model (Tullock, 1967), applied to a situation in which two groups $(j=1,2)$ of $n=3$ players each compete for a prize that is shared equally among the members of the winning party (Katz et al., 1990). The prize thus constitutes a public good, with an individual valuation of $v$. Initially, each player is endowed with the same amount of resources, $\omega$. All players have to simultaneously and independently decide how much of their endowment they want to invest into the conflict. While spending effort is costly for the individual, it increases the chance of the own group winning the contest. The performance of the group thereby depends on the joint effort of all members, i.e., efforts are perfect substitutes. Formally, let $x_{i, j}$ denote the effort (resources) spend by player $i$ in group $j$. A group's performance is then determined by the sum of all efforts, i.e., $X_{j}=\sum_{i=1}^{N} x_{i, j}$. The probability of winning the contest depends on the relative performance of both groups. Following Tullock (1980), we use the following contest success function:

$$
p_{j}\left(X_{1}, X_{2}\right)=\left\{\begin{array}{cl}
\frac{X_{j}}{X_{1}+X_{2}} & X_{1}+X_{2}>0 \\
\frac{1}{2} & \text { otherwise }
\end{array}\right.
$$

The expected payoff of player $i$ in group $j$ is thus given by

$$
\pi_{i, j}\left(x_{i, j}, X_{1}, X_{2}\right)=\omega-x_{i, j}+p_{j} \cdot v
$$

Within this framework, we consider the following four institutions:

- Autonomy: Each group member decides individually and simultaneously about the own conflict investment.

- Dictatorship: One group member has full decision power over all group members' investments. Investment levels can differ across members.

- Restricted Dictatorship: One group member determines common investment level, i.e., $X_{j}=n \cdot x_{i, j}$.

- Democracy: Each group member first makes a proposal about a common investment level. After all proposals have been collected, the median proposal within each group is implemented for each group member.

In the following, we derive the Nash equilibrium predictions under the assumption that players are risk-neutral and only care about their own monetary payoff. 


\section{Symmetric contests}

\section{Autonomy}

By inserting (3) into (4) and taking the first derivative with respect to $x_{i, j}$, for individual $i$ in group $j=1$ we obtain the following first-order condition:

$$
\frac{\partial \pi_{i, 1}}{\partial x_{i, 1}}=\frac{X_{2}}{\left(X_{1}+X_{2}\right)^{2}} \cdot v-1
$$

By setting this equation equal to zero and solving for $X_{1}$ we obtain the following bestresponse function:

$$
X_{1}=\sqrt{v X_{2}}-X_{2}
$$

In symmetric contests between two identical groups, in the symmetric Nash equilibrium we have $X_{1}=X_{2}=X$, and thus:

$$
X^{*}=\frac{v}{4}
$$

\section{Dictatorship}

Dictators determine a vector of investments $\mathbf{x}=\left(x_{i}, x_{-i}\right)$, where $x_{i}, x_{-i} \in[0, \omega]$ are the investment levels of themselves and their group members. Purely self-interested dictators always invest the maximum possible amount of the other groups members, as any investment by others increases the groups's winning probability (and hence the dictators' expected payoffs) without causing them any costs. Hence, we have $x_{-i}=\omega$. The group's total investment can thus be rewritten as $X_{j}=x_{i, j}+(n-1) \cdot \omega$.

By taking the first derivative of the dictator's objective function with respect to $x_{i, j}$, for dictator $i$ in group $j=1$ we obtain the following first-order condition:

$$
\frac{\partial \pi_{i, 1}}{\partial x_{i, 1}}=\frac{X_{2}}{\left(X_{1}+X_{2}\right)^{2}} \cdot v-1
$$

By setting this equation equal to zero and solving for $x_{i, 1}$ we obtain the following bestresponse function:

$$
x_{i, 1}=\sqrt{v X_{2}}-X_{2}-(n-1) \cdot \omega
$$

In symmetric contests between two identical groups, in the symmetric Nash equilibrium we have $x_{1}=x_{2}=x$, and thus:

$$
x^{*}=\frac{v}{4}-(n-1) \cdot \omega
$$

Hence, dictators only invests themselves $\left(x^{*}>0\right)$, if $\frac{v}{4}>(n-1) \cdot \omega$, i.e., if the prize is 
sufficiently large and/or the endowment of the other group members is sufficiently small. Note that the threshold $\frac{v}{4}$ is identical to the unique Nash equilibrium under the Autonomy. Intuitively, dictators are only willing to invest any positive amount themselves if the aggregated funds of the other group members are smaller than the investment amount which is optimal from an individual point of view when all group members decide autonomously.

\section{Restricted Dictatorship}

The dictator determines a common investment level for all group members, i.e., $X_{j}=n \cdot x_{i, j}$. The objective function of dictator $i$ in group $j=1$ can thus be rewritten as:

$$
\pi_{i, 1}\left(x_{i, 1}, X_{2}\right)=\omega-x_{i, 1}+\frac{n x_{i, 1}}{n x_{i, 1}+X_{2}} \cdot v
$$

By taking the first derivative of (11) with respect to $x_{i, 1}$ we obtain the following first-order condition:

$$
\frac{\partial \pi_{i, 1}}{\partial x_{i, 1}}=\frac{n \cdot X_{2}}{\left(n x_{i, 1}+X_{2}\right)^{2}} \cdot v-1
$$

By setting this equation equal to zero and solving for $x_{i, 1}$ we obtain the following bestresponse function:

$$
x_{i, 1}=\frac{\sqrt{n v X_{2}}-X_{2}}{n}
$$

In symmetric contests between two identical groups, in the symmetric Nash equilibrium we have $x_{1}=x_{2}=x$, and thus:

$$
x^{*}=\frac{v}{4}
$$

Given that $X_{j}=n \cdot x_{i, j}$, for the total group investments we thus get:

$$
X^{*}=\frac{n v}{4}
$$

\section{Democracy}

In this institution, conflict investments are determined by voting. In particular, each group member can make a proposal by submitting a common investment level $\tilde{x}$. Subsequently, the median proposal within each group is implemented for all group members.

As a result of this aggregation method, there is a vast range of Nash equilibria, both with regard to the individual proposals as well as with regard to the group's total investment. For example, any profile in which all players in a group make the same proposal is a Nash equilibrium, because the median vote will not change if any single player changes her vote. As a result, there are multiple symmetric Nash equilibria in which both groups invest the 
same amounts into conflict, including one in which all players propose zero investments, as well as one in which all members propose maximum investments. In addition, there are also multiple asymmetric equilibria in which proposals are the same within but not between groups.

To circumvent the issue of multiplicity of Nash equilibria, as a refinement criterion, we assume that players coordinate on an investment level that is Pareto efficient from the own group's point of view. That is, we only focus on those equilibria which are robust against joint deviations from a coalition of players within the same group. This refinement criterion is related to the concepts of strong Nash equilibrium (Aumann, 1959) and coalition-proof Nash equilibrium (Bernheim et al., 1987), and has been applied to similar contexts before (see e.g., Gürtler, 2008). To illustrate the intuition behind this refinement, imagine the situation in which all players in both groups propose an investment level of zero. This situation constitutes a Nash equilibrium as no player has an incentive to deviate unilaterally. Yet, all group members would prefer to jointly deviate to a different strategy profile, where, again, no player has an incentive to unilaterally deviate. In particular, if the rivaling group invests nothing into the conflict, all members of the other group would be strictly better off when jointly deviating to, e.g., a strategy profile of one, in which case the group would win the conflict with certainty (rather than with probability of 0.5 when sticking to the strategy profile of zero).

Applying this logic to both groups, it follows that in symmetric contests the only remaining Nash equilibria are the ones in which total investments in both groups are equal to $X^{*}=\frac{n v}{4}$. Note that this is the same prediction as in the restricted dictatorship. The intuition for this is straightforward, as a coalition of players in the democracy effectively faces the same incentives as the dictator in the restricted dictatorship: When deviating jointly and increasing the proposed investment level by one unit, a group's total investment level increases by $n$ units (each of the $n$ group members has to follow the binding vote and increase their investment by one unit). Yet, each individual only bears a share of $\frac{1}{n}$ of the total investment costs. As a result, when applying the refinement criterion of Pareto efficiency within groups, we have a unique prediction with regard to the group's total investments. Yet, similar to the case of the autonomy, there are multiple equilibria with regard to the individual proposals, as any combination of proposals where the median proposal is equal to $\frac{v}{4}$ constitutes an equilibrium. 


\section{Asymmetric contests}

To derive the predictions for the asymmetric contests we can use and cross-match the bestresponse functions as derived above (see equations (6), (9), and (13)).

\section{Autonomy vs. Restricted Dictatorship}

For the asymmetric contest between an Autonomy $(j=1)$ and a Restricted Dictatorship $(j=2)$, we have:

$$
X_{1}^{A U T}=\sqrt{v X_{2}}-X_{2}
$$

and

$$
X_{2}^{R D I C}=\sqrt{n v X_{1}}-X_{1}
$$

By inserting these two best-response functions into each other and solving for $X_{1}^{A U T}$ and $X_{2}^{R D I C}$, respectively, we obtain:

$$
X_{A U T, R D I C}^{*}=\frac{n v}{(n+1)^{2}}
$$

and

$$
X_{R D I C, A U T}^{*}=\frac{n^{2} v}{(n+1)^{2}}
$$

Note that for $n>1$, in both cases the predicted investments are lower than the ones for the symmetric contests.

\section{Autonomy vs. Dictatorship}

For the asymmetric contest between an Autonomy $(j=1)$ and a Dictatorship $(j=2)$, we have:

$$
X_{1}^{A U T}=\sqrt{v X_{2}}-X_{2}
$$

and

$$
x_{2}^{D I C}=\sqrt{v X_{1}}-X_{1}-(n-1) \cdot \omega
$$

Since a self-interested dictator always invests the maximum possible amount from his group members, it follows that $X_{2}^{D I C} \geq(n-1) \cdot \omega$. By inserting $(n-1) \cdot \omega$ into the best-response function of the autonomy, it is easy to see that members of the autonomy are only willing to invest any positive amount into the conflict if $v>(n-1) \cdot \omega$, i.e., if the prize is sufficiently large and/or the disposable resources of the dictator's group members are sufficiently small.

For the parameters of our experiment $(n=3, v=100, \omega=100)$, this condition is not fulfilled. Hence, given the dictator's minimum investment of $(n-1) \cdot \omega=200$, the members of the autonomy prefer to stay out of the conflict and invest nothing. As a consequence, given that the dictator group will win the contest with certainty, the dictator has no incentive to 
invest anything himself. We thus have $X_{A U T, D I C}^{*}=0$ and $X_{D I C, A U T}^{*}=200$ as the unique Nash equilibrium.

\section{Restricted Dictatorship vs. Dictatorship}

For the asymmetric contest between a Restricted Dictatorship $(j=1)$ and a Dictatorship $(j=2)$, we have:

$$
X_{1}^{R D I C}=\sqrt{n v X_{2}}-X_{2}
$$

and

$$
x_{2}^{D I C}=\sqrt{v X_{1}}-X_{1}-(n-1) \cdot \omega
$$

Similar to the case above, we know that the dictator in the discriminatory dictatorship invests at least $(n-1) \cdot \omega$. Inserting this into the best reply function of the restricted dictatorship, we find that the dictator under this regime is only willing to invest a positive amount if $n v>(n-1) \cdot \omega$. In our experiment this condition is fulfilled. In particular, given our parameters, we find that if the dictator in the discriminatory dictatorship invests $(n-1) \cdot \omega=200$, the best response of the dictator in the restricted dictatorship is to invest $X_{1}^{R D I C}=\sqrt{n v(n-1) \cdot \omega}-(n-1) \cdot \omega=\sqrt{60000}-200 \approx 44.95$.

To check whether this can be part of an equilibrium, we need to check whether $(n-1) \cdot \omega$ is also a best reply for the dictator in the discriminatory dictatorship. Given the parameter of our experiment, this is indeed the case. In general, a discriminatory dictator is only willing to invest anything himself if $v>\frac{\left((n-1) \omega+X_{1}\right)^{2}}{X_{1}}$. Given $X_{1}^{R D I C}$ and given our group size of $n=3$ and $\omega=100$, in our case the dictator would be only willing to invest if $v>\frac{60000}{44.948974} \approx 1334.85$. Since in our experiment $v=100$, the best reply of the dictator is indeed to not invest himself but to set $x_{i}=0$ and $x_{-i}=100$. We thus have $X_{R D I C, D I C}^{*}=44.95$ and $X_{D I C, R D I C}^{*}=200$ as the unique Nash equilibrium.

\section{Asymmetric contests involving democracies}

As before, without further assumptions, there is a vast range of equilibria for democracies also in asymmetric contests. Similar to the logic above, any profile in which all players in the group make the same proposal is a Nash equilibrium, because the median vote will not change if any single player changes her vote.

If, however, we again use the refinement criterion from above, assuming that players coordinate on those equilibria that are Pareto efficient from the own group's point of view (i.e., those equilibria which are robust against joint deviations from a coalition of players), the prediction for the group's total investments are the same as for the restricted dictatorship. The intuition for this is the same as for symmetric contests. A coalition of players in the Democracy institution faces the exact same incentives as a dictator in the Restricted Dictatorship: When deviating jointly and increasing the proposed investment level by one unit, a group's total investment level increases by $n$ units (each of the $n$ group members has to follow the binding vote and increase their investment by one unit), but each individual 
only bears a share of $\frac{1}{n}$ of the total investment costs. It thus follows that when applying the refinement criterion of Pareto efficiency within groups, the aggregated investments are predicted to be the same across both institutions.

Table B1 provides a summary of the predictions for both symmetric and asymmetric contests using the parameters from our experiment $(n=3, v=100, \omega=100)$.

\begin{tabular}{|c|c|c|c|c|}
\hline $\begin{array}{l}\text { Own } \\
\text { Institution }\end{array}$ & $\begin{array}{l}\text { Opponent's } \\
\text { institution }\end{array}$ & $\begin{array}{l}\text { Group } \\
\text { investment }\end{array}$ & $\begin{array}{l}\text { Winning } \\
\text { probability }\end{array}$ & $\begin{array}{c}\text { (Mean) Expected } \\
\text { payoff }\end{array}$ \\
\hline \multicolumn{5}{|c|}{ Symmetric contests } \\
\hline AUT & AUT & 25 & 0.5 & 141.67 \\
\hline DEM & DEM & 75 & 0.5 & 125 \\
\hline $\mathrm{DIC}$ & $\mathrm{DIC}$ & 200 & 0.5 & 83.33 \\
\hline RDIC & RDIC & 75 & 0.5 & 125 \\
\hline \multicolumn{5}{|c|}{ Asymmetric contests } \\
\hline AUT & DEM & $18.75,56.25$ & $0.25,0.75$ & $118.75,156.25$ \\
\hline AUT & DEM & $18.75,56.25$ & $0.25,0.75$ & $118.75,156.25$ \\
\hline AUT & DIC & 0,200 & 0,1 & 100, 133.33 \\
\hline DEM & RDIC & 75,75 & $0.5,0.5$ & 125,125 \\
\hline DEM & DIC & $44.95,200$ & $0.18,0.82$ & $103.02,115.33$ \\
\hline RDIC & DIC & $44.95,200$ & $0.18,0.82$ & $103.02,115.33$ \\
\hline
\end{tabular}

Notes: In the Dictatorship (DIC), dictators are always predicted to invest 0 , while the other two group members are predicted to invest 100. The predictions for the Democracy (DEM) are derived using the additional assumption that group members coordinate on the equilibrium in which no coalition within a group has an incentive to jointly deviate. For the asymmetric contests, the first number in each column refers to the own institution, while the second refers to the opponent's institution.

Table B1: Benchmark predictions. 


\section{Experimental Instructions (translated from German)}

\section{General Instructions}

Welcome and thank you for your participation in this experiment. For your participation and punctual arrival, you receive $€ 4$. You can earn an additional substantial amount of money in this experiment. The exact amount you will receive depends on your decisions and the decisions of the other participants. It is therefore very important that you read the following instructions carefully.

During the experiment, you are not allowed to communicate with other participants of the experiment or any person outside the laboratory. For this reason, all mobile phones must be switched off. If you have questions about the instructions or the study, please raise your hand. We will privately answer your question at your place. Disregarding these rule leads to the exclusion from this experiment and from all payments.

In this study all earnings are first calculated in points. You will receive the sum of your earnings in cash at the end of this study, using the following exchange rate:

$$
10 \text { Points }=2.5 \text { Eurocent }
$$

The experiment consists of two parts (Part I and Part II). In the following we will first explain to you the rules of Part I. You will receive the instructions for Part II once Part I is finished.

\section{Part I}

Part I of this study consists of twenty (20) consecutive periods. The decision situation in each of the 20 periods is identical.

At the beginning of Part I, all participants are randomly matched into groups of three (3) participants. During the experiment, you will interact with the two other members of your group, as well as with another group of three participants. The composition of the groups remains the same across all 20 periods. This means that in Part I you will always interact with the same people. Neither during nor after the experiment you will learn the identity of the people you interacted with. All payments at the end of the study will therefore be made anonymously.

\section{Competition for a prize}

In each of the 20 periods, your group and the other group compete for a prize of 300 points. The chance of your group winning the prize thereby depend on how many points your group and the other group invest into a contest account. 


\section{Investing into the Contest Account/Treatment specific]}

Autonomy treatment only: At the beginning of each of the 20 periods, each group member receives an endowment of 100 points. You can keep these points either for yourself or invest them (fully or partly) into the contest account of your group. That is, in each period you decide on how many points you want to invest into the contest account of your group. The total amount of points in the contest account of your group is determined by the sum of investments of all group members. Each point not invested into the contest account remains automatically on your private account, which will be added to your earnings in that period.

Democracy treatment only: At the beginning of each of the 20 periods, each group member receives an endowment of 100 points. You can keep these points either for yourself or invest them (fully or partly) into the contest account of your group. In each period, you can make a proposal of how many points each group member (including you) should invest into the contest account of your group. Your two group members each also make a proposal. After that, the proposals are sorted by size, and the middle proposal is implemented for all group members. This proposal thus determines how many points each group member must invest into the contest account. The total amount of points in the contest account of your group is determined by the sum of investments of all group members $(=3 \times$ implemented proposal). Each point not invested into the contest account remains automatically on your private account, which will be added to your earnings in that period.

Dictator treatment only: At the beginning of each of the 20 periods, each group member receives an endowment of 100 points. You can keep these points either for yourself or invest them (fully or partly) into the contest account of your group. Before the start of the first period, one group member will randomly be selected. In each period, this group member decides how many points each group member must invest into the contest account of your group. The investment into the contest account can thereby differ for each group member. The other two non-selected group members have no decision to make. At the beginning of the experiment you will be informed in which role you are. The total amount of points in the contest account of your group is determined by the sum of investments of all group members. Each point not invested into the contest account remains automatically on your private account, which will be added to your earnings in that period.

Restricted dictator treatment only: At the beginning of each of the 20 periods, each group member receives an endowment of 100 points. You can keep these points either for yourself or invest them (fully or partly) into the contest account of your group. Before the start of the first period, one group member will randomly be selected. In each period, this group member decides how many points each group member must invest into the contest account of your group. The investment into the contest account thereby has to be the same for all group members. The other two non-selected group members have no decision to make. At the beginning of the experiment you will be informed in which role you are. The total amount of points in the contest account of your group is determined by the sum of 
investments of all group members $(=3 \times$ implemented investment decision of the selected group member). Each point not invested into the contest account remains automatically on your private account, which will be added to your earnings in that period.

The other group is in the exact same decision situation and decides on the investments into the contest account in the exact same manner as your group.

\section{Determining the chance of winning}

Once both groups have decided on how many points to invest into their contest account, the probability that your group and the probability that the other group will win the contest are determined.

The winning probability of both groups thereby depends on how many points your group and the other group invested into their respective contest account. In general:

The probability that your group wins the contest is

- The higher the more points your group invests into the contest account

- The lower the more points the other group invests into their contest account

The other group is in the analogues but reversed situation. That is, the probability that the other group wins the contest is

- The lower the more points your group invests into the contest account

- The higher the more points the other group invests into their contest account

The exact winning probability of your group is calculated as follows:

Total amount of points invested in your group

Total amount of points invested in both groups together

\section{Examples:}

1. If your group invests a total of 100 points into the contest account and the other group also invests 100 points into their contest account, then the total amount of invested points by both groups together is 200 points. The probability that your group wins the contest therefore is $\frac{100}{200}=\frac{1}{2}=50 \%$. The probability that the other group wins the contest is $\frac{100}{200}=\frac{1}{2}=50 \%$.

2. If your group invests a total of 40 points into the contest account and the other group invests 120 points into their contest account, then the total amount of invested points by both groups together is 160 points. The probability that your group wins the contest

then is $\frac{40}{160}=\frac{1}{4}=25 \%$. The probability that the other group wins the contest then is $\frac{120}{160}=\frac{3}{4}=75 \%$. 


\section{Important:}

- If one group does not invest any points into their contest account, then the other group wins the contest with certainty.

- If none of the two groups invest any points into their respective contest account, then the winner will be determined randomly.

\section{Determining the winner of the contest}

After the winning probabilities have been determined, a random draw of the computer based on these probabilities will determine, which group wins the contest in this period.

The prize in each period is 300 points. The prize is always allocated equally among the three group members of the winning team (irrespective of how many points each group member invested into the contest account). This means that the three members of the winning group each receive 100 points from the contest. The members of the other group receive 0 points from the contest in this period.

\section{Your period income}

Your income in a period is determined by the sum of earnings from your private account (= amount of points not invested into the contest) plus your earnings from the contest.

If your group wins the contest:

$$
\text { Your income }=100 \text { - your invested points }+100
$$

If your group does not win the contest:

$$
\text { Your income }=100-\text { your invested points }
$$

\section{End of a period}

At the end of each period, after all participants have made an investment decision, you will receive information about:

- The amount of points that each group member invested into the contest account of your group

- The total amount of points the other group invested into their contest account

- The resulting winning probabilities of both groups 
- The winner of the contest

- The income of each member of your group

After that a new period starts. Each group member again receives an endowment of 100 points and your group can again win a prize of 300 points. Your total income from Part I is determined by the sum of your earnings from all 20 periods. You should therefore take your decisions in all periods seriously.

\section{Control questions}

\section{Note: These questions are taken from the Democracy treatment.}

Please answer the following questions. The purpose of these questions is to ensure that all participants fully understand the instructions.

Assume that the proposals of the three members in your group are: 10, 40, and 100 .

Question 1: What are the total investments into the contest account in your group?

Further assume that the proposals of the three members in the other group are: 0,10 , and 50 .

Question 2: What are the total investments into the contest account in the other group?

What is the winning probability

- Question 3: In your group (in \%)?

- Question 4: In the other group (in \%)?

Question 5: What is the winning probability (in \%) in your group if the proposals in the other group are 0,40 , and 90 instead of 0,10 , and 50 (as before)?

Assume that your group won the contest in this period and that the proposals of investments in your group were: You: 50, Group member 1: 20, Group member 2: 80.

Question 6: How many points do you have on your private account?

Question 7: How many points does group member 1 has on his/her private account?

Question 8: How many points does group member 2 has on his/her private account?

Question 9: How many points do you receive from the contest?

Question 10: How many points does group member 1 receive from the contest?

Question 11: How many points does group member 2 receive from the contest?

Question 12: What is your total income in this period?

Question 13: What is the total income of group member 1 in this period?

Question 14: What is the total income of group member 2 in this period?

Question 15: How many points do the members of the other group receive from the contest in this period? 


\section{Part II}

Part II of this study also consists of a repeated contest between two groups of three participants each. The composition of groups in Part II is thereby different from the one in Part I. At the beginning of Part II all groups are first dissolved. After that, new groups are randomly formed. You therefore play with different participants in your group. Also the composition of participants in the other group is different.

In Part II there are twenty (20) consecutive periods. The new composition of groups remains the same across all these periods. Differently from Part I, each group can now determine according to which rule points can be invested into the contest account of the own group. You can choose between four different rules:

- Rule 1: Each group member can decide individually how many points to invest into the contest account of the group. The total investment of your group into the contest account is determined by the sum of the individual investments.

- Rule 2: Each group member makes a proposal of how many points each group member should invest into the contest account of your group. After that, the proposals are sorted by size, and the middle proposal is implemented for all group members. This proposal thus determines how many points each group member must invest into the contest account. This means that the investments of all group members are always the same. The total amount of points in the contest account of your group is determined by the sum of investments of all group members $(=3 \times$ implemented proposal).

- Rule 3: Before the start of the first period, one group member will randomly be selected. In each period, this group member decides how many points each group member must invest into the contest account of your group. The investment into the contest account thereby has to be the same for all group members. The other two non-selected group members have no decision to make. The total amount of points in the contest account of your group is determined by the sum of investments of all group members $(=3 \times$ implemented investment decision of the selected group member).

- Rule 4: Before the start of the first period, one group member will randomly be selected. In each period, this group member decides how many points each group member must invest into the contest account of your group. The investment into the contest account can thereby differ for each group member. The other two non-selected group members have no decision to make. At the beginning of the experiment you will be informed in which role you are. The total amount of points in the contest account of your group is determined by the sum of investments of all group members.

\section{Deciding on the rule}

Before the start of Part II, you can state for each of the four rules whether you support that rule or not. You can support as many rules as you want. 
After all group members have made their decisions, we count, separately for each group, which rule received the largest amount of support. This rule will then be implemented for your group for all 20 periods in Part II. If there is more than one rule with the largest amount of support, one of the rules with the largest number of votes will be implemented at random.

The other group decides like your group about which rule to adopt. Please note that the other group might implement a rule that is different from the one implemented in your group. Before the start of the first period you will be informed about the rule that is implemented in your group and the rule that is implemented in the other group. After that, the 20 periods start.

\section{Your total income}

Your total income from Part II is determined by the sum of your earnings from all 20 periods. At the end of the experiment, your income from Part I and Part II will be added up and exchanged into Euros. At the end of the experiment, you will receive this amount plus the $€ 4$ show-up fee for your punctual arrival in cash. 